\title{
Nuclear forensic signatures and structural analysis of uranyl oxalate, its products of thermal decomposition and Fe impurity dopant
}

\author{
Nathan B. A. Thompson ${ }^{1}$ D $\cdot$ Martin C. Stennett ${ }^{1} \cdot$ Matthew R. Gilbert $^{2} \cdot$ Neil C. Hyatt $^{1}$
}

Received: 12 October 2020 / Accepted: 27 November 2020 / Published online: 6 January 2021

(C) The Author(s) 2021

\begin{abstract}
Uranyl oxalate $\left(\mathrm{UO}_{2} \mathrm{C}_{2} \mathrm{O}_{4} \cdot \mathrm{xH}_{2} \mathrm{O}\right)$ may exist at the back-end of the nuclear fuel cycle (NFC) as an intermediate in spent fuel reprocessing. The conditions used in aqueous reprocessing and thermal treatment can affect the physical and chemical properties of the material. Furthermore, trace impurities, such as Fe, may incorporate into the structure of these materials. In nuclear forensics, understanding relationships between processing variables aids in determination of provenance and processing history. In this study, the thermal decomposition of $\mathrm{UO}_{2} \mathrm{C}_{2} \mathrm{O}_{4} \cdot 3 \mathrm{H}_{2} \mathrm{O}$ and phase analysis of its thermal products are examined. Their morphologies are discussed with respect to a matrix of solution processing conditions.
\end{abstract}

Keywords Uranyl oxalate $\cdot$ Morphology $\cdot$ Nuclear forensics $\cdot$ Signatures $\cdot$ Iron impurity

\section{Introduction}

Uranyl oxalate $\left(\mathrm{UO}_{2} \mathrm{C}_{2} \mathrm{O}_{4} \cdot \mathrm{xH}_{2} \mathrm{O}\right)$ is one of a number of intermediate compounds that can be formed during the reprocessing of spent nuclear fuel [1]. The process occurs by addition of oxalic acid to uranyl nitrate, forming an intermediate oxalate precipitate, which is calcined to uranium oxide $\left(\mathrm{U}_{3} \mathrm{O}_{8}\right)$ for eventual storage. Other intermediates exist, such as uranyl peroxide $\left(\left[\left(\mathrm{UO}_{2}\right)\left(\mathrm{O}_{2}\right)\left(\mathrm{H}_{2} \mathrm{O}\right)_{2}\right] \cdot 2 \mathrm{H}_{2} \mathrm{O}\right)$, which is produced following a similar processing route and has been extensively studied for its material properties [2-6]. Furthermore, some recent characterisations have been focused on the nuclear forensic implications of uranyl peroxides and its oxides [7]. Neither the material characteristics nor the nuclear forensic signatures of the oxalate intermediate

Nathan B. A. Thompson

nbathompson1@sheffield.ac.uk

Martin C. Stennett

m.c.stennett@sheffield.ac.uk

Matthew R. Gilbert

matthew.gilbert@awe.co.uk

Neil C. Hyatt

n.c.hyatt@sheffield.ac.uk

1 Department of Materials Science and Engineering, University of Sheffield, Sir Robert Hadfield Building, Sheffield S1 3JD, UK

2 AWE, Aldermaston, Reading RG7 4PR, UK have been reported extensively. One study by Tel et al. particularly focused on its material characteristics pertaining to the front-end of the nuclear fuel cycle (NFC), while no such studies can be found relating to the back-end; [8] it is important to consider the context of each stage of the NFC, as the needs and uses of materials can vary between them [9]. To address these shortcomings, this study presents a material characterisation of uranyl oxalate at the back-end of the NFC, and its products of thermal decomposition, with consideration for nuclear forensic implications. In particular, the reagents and solution processing conditions used here to produce uranyl oxalate, namely uranyl nitrate and oxalic acid, are of particular concern to back-end processing. Heat treatment to stable oxides, such as $\mathrm{U}_{3} \mathrm{O}_{8}$, are also associated with the eventual storage of reprocessed uranium compounds. Additionally, consideration for potential dopants found in the NFC, such as Fe, is made. Such a study in the field of nuclear forensics is warranted, as determining the provenance of intercepted materials helps contribute to national security efforts $[10,11]$ There is a need, therefore, to expand the nuclear forensic database to a wide range of nuclear materials that may occur industrially.

Uranyl oxalate usually exists in the trihydrate form $\left(\mathrm{UO}_{2} \mathrm{C}_{2} \mathrm{O}_{4} \cdot 3 \mathrm{H}_{2} \mathrm{O}\right)$ at room temperature and has previously been shown to decompose to the monohydrate $\left(\mathrm{UO}_{2} \mathrm{C}_{2} \mathrm{O}_{4} \cdot \mathrm{H}_{2} \mathrm{O}\right)$ and anhydrate $\left(\mathrm{UO}_{2} \mathrm{C}_{2} \mathrm{O}_{4}\right)$ at higher temperatures $[12,13]$. At temperatures above $400{ }^{\circ} \mathrm{C}$, it is reported that uranium oxides are formed, which may be confirmed 
by coupling thermogravimetric analysis (TGA) with X-ray diffraction (XRD). To expand the nuclear forensic toolkit as applied to these materials, X-ray absorption near-edge spectroscopy (XANES) analysis was also considered. Previously, in consideration of the provenance of uranium ore concentrates, this has been shown as a useful tool for the characterisation of uranium oxidation state and coordination environment [14]. In the context of nuclear forensics, this is a significant in the fingerprinting of materials based on their physiochemical properties. Additionally, by expanding this analysis to extended X-ray absorption fine structure (EXAFS), information about the local atomic environment can be obtained.

Particle morphology is an important nuclear forensic signature, as it is well known that solution processing conditions can greatly affect the resultant particle form and size [3]. Work on plutonium oxalate, for example, has elucidated that particles exhibited a range of morphologies, such as rosettes and square plated particles, which varied depending on the conditions employed [15]. Interestingly, the order in which reagents were added (strike order) has been suggested as a contributing factor in the morphology selection. The effect of variable processing conditions on particle morphology was therefore examined for the compounds in this study, with the objective of interpreting the interactions of parameters on the final particle form. To achieve this, a fractional factorial matrix was designed and utilised, to examine the interactions and relationships between experiment variables. It is also known that chemical impurities can affect the morphology and particle size distribution of solution grown materials $[16,17]$. To investigate this effect on uranyl oxalate, an experiment was conducted into the doping of uranyl oxalate with Fe. This is fundamental knowledge to nuclear forensics, as industrial samples often contain impurities; this includes iron, of which, impurities may typically be found in concentrations up to $80 \mathrm{ppm}$ in some reprocessed oxides [18]. Fe contaminants in industrial samples may arise from sources such as stainless steel, which is used extensively in industrial nuclear components [19].

\section{Experimental methods}

\section{Sample preparation}

\section{Standard batch for TGA, XRD and XAS}

A standard batch of $\mathrm{UO}_{2} \mathrm{C}_{2} \mathrm{O}_{4} \cdot 3 \mathrm{H}_{2} \mathrm{O}$ was produced in solution by dropwise addition of oxalic acid $\left(\mathrm{C}_{2} \mathrm{H}_{2} \mathrm{O}_{4}, 1.5 \mathrm{M}\right)$ to uranyl nitrate hexahydrate $\left(\mathrm{UO}_{2}\left(\mathrm{NO}_{3}\right)_{2} \cdot 6 \mathrm{H}_{2} \mathrm{O}, \mathrm{UNH}, 1.0 \mathrm{M}\right)$, using ultra-high quality Millipore water (UHQ, 18.2 $\Omega$ ). A slow rate of stirring $(20 \mathrm{~Hz})$ was used, along with a constant reaction temperature of $75^{\circ} \mathrm{C}$, using a stirrer hotplate. The resultant pale-yellow precipitate was filtered under reduced pressure and dried for $48 \mathrm{~h}$ in air. The $\mathrm{UO}_{2} \mathrm{C}_{2} \mathrm{O}_{4} \cdot 3 \mathrm{H}_{2} \mathrm{O}$ powder was heated under nitrogen atmosphere to temperatures of $150,250,400$ and $800{ }^{\circ} \mathrm{C}$ in a Netzsch TG 449 F3 Jupiter simultaneous thermal analyser at $10^{\circ} \mathrm{C} / \mathrm{min}$, to ensure accurate and precise temperature and gas flow control.

\section{Matrix sample preparation for SEM}

A separate batch of $\mathrm{UO}_{2} \mathrm{C}_{2} \mathrm{O}_{4} \cdot 3 \mathrm{H}_{2} \mathrm{O}$ was prepared similarly to the standard, instead employing a reduced factorial matrix of solution processing conditions; varied factors included concentration of UNH (1.0 or $1.5 \mathrm{M})$, oxalic acid concentration $(1.5$ or $2.0 \mathrm{M})$ and order of reagent addition (strike order, direct or reverse addition). The construction of this matrix is detailed in "Fractional Factorial Matrix" section, and described elsewhere [20]. These samples were heated to $800{ }^{\circ} \mathrm{C}\left(\mathrm{U}_{3} \mathrm{O}_{8}\right)$, and with $\mathrm{UO}_{2} \mathrm{C}_{2} \mathrm{O}_{4} \cdot 3 \mathrm{H}_{2} \mathrm{O}$, analysed for their morphological forensic signatures. One batch of samples was prepared outside of the matrix of processing conditions, labelled with an 'e' (e.g. Sample S5e), indicating that they were 'extra' to the matrix. These samples were used to demonstrate the effect of processing conditions beyond those primarily studied in this paper. All samples prepared as described in this section were stored in airtight plastic vials and analysed within a period of 1 month. Samples were of the same relative age at each stage of analysis.

\section{Impure sample preparation}

A stock solution of uranyl nitrate hexahydrate was prepared as described above. A solution of $\mathrm{Fe}$ nitrate $\left(\mathrm{Fe}\left(\mathrm{NO}_{3}\right)_{3} \cdot 9 \mathrm{H}_{2} \mathrm{O}\right)$ was prepared in UHQ at a concentration of $0.06 \mathrm{M}$. The impurity was introduced to the UNH solution separately by dropwise addition from a pipette. $\mathrm{UO}_{2} \mathrm{C}_{2} \mathrm{O}_{4} \cdot 3 \mathrm{H}_{2} \mathrm{O}$ was produced as previously described. A fraction of the impure $\mathrm{UO}_{2} \mathrm{C}_{2} \mathrm{O}_{4} \cdot 3 \mathrm{H}_{2} \mathrm{O}$ sample was heated to $800{ }^{\circ} \mathrm{C}$, as previously described.

\section{Thermogravimetric analysis with differential thermal analysis and mass spectrometry (TGA-DTA-MS)}

Thermogravimetric, differential thermal analysis and mass spectrometry (TGA-DTA-MS) were carried out simultaneously by heating $20 \mathrm{mg}$ of $\mathrm{UO}_{2} \mathrm{C}_{2} \mathrm{O}_{4} \cdot 3 \mathrm{H}_{2} \mathrm{O}$ sample from 25 to $850{ }^{\circ} \mathrm{C}$ at a rate of $10{ }^{\circ} \mathrm{C} / \mathrm{min}$ under nitrogen atmosphere, in a Netzch TG 449 F3 Jupiter simultaneous thermal analyser. Data were corrected to a baseline correction. The 
melting points of elemental In $\left(156.6{ }^{\circ} \mathrm{C}\right)$, Sn $\left(231.9{ }^{\circ} \mathrm{C}\right)$, $\mathrm{Zn}\left(419.5{ }^{\circ} \mathrm{C}\right), \mathrm{Al}\left(660.3{ }^{\circ} \mathrm{C}\right), \mathrm{Ag}\left(961.8{ }^{\circ} \mathrm{C}\right)$, and $\mathrm{Au}$ $\left(1064.2{ }^{\circ} \mathrm{C}\right)$ were used to calibrate the TGA temperature. The TGA microbalance was automatically calibrated using an internal weight prior to each run. A 64 channel QMS 403 D Aëolos mass spectrometer was used for analysis of evolved gases. Obtained data was processed with OriginPro 2017 software.

\section{Hygroscopicity measurement}

The initial weight of the $\mathrm{UO}_{2} \mathrm{C}_{2} \mathrm{O}_{4} \cdot 3 \mathrm{H}_{2} \mathrm{O}$ sample was measured using a Mettler Toledo ${ }^{\circledR}$ Semi-Micro balance. The rate of sample weight change after thermal decomposition to $250{ }^{\circ} \mathrm{C}$ was measured once every minute, using the same balance over a period of $20 \mathrm{~min}$, in air.

\section{X-ray diffraction (XRD)}

A Bruker D2 Phaser fitted with a position sensitive detector was used to obtain X-Ray diffraction data with a $\mathrm{Cu}$ $\mathrm{K} \alpha$ source; diffraction patterns were collected between $10<2 \theta<70^{\circ}$ at $3 \%$ min, analysed using Bruker's DIFFRAC. EVA software and processed with OriginPro 2017 software.

\section{X-ray absorption spectroscopy}

X-ray absorption spectroscopy was carried out on Beamline B18 at the Diamond Light Source synchrotron (DLS), United Kingdom. Uranyl oxalate samples were measured at room temperature, in transition mode, at the U L3-edge (17.166 keV) using an Si double crystal monochromator. For measurement of the $\mathrm{Fe}$ absorber atom in the doped samples, data were collected at the Fe K-edge $(7.112 \mathrm{keV})$ in fluorescence mode. Samples were pelletised after mixing with polyethylene glycol (PEG) to a diameter of $3 \mathrm{~mm}$ and loaded onto a Perspex grid. The obtained data were analysed using the Demeter analysis system; data normalisation and analysis was carried out using Athena, while fitting was performed in Artemis (EXAFS only) and plotted for visualisation in Origin software (Origin(Pro) version 2017, OriginLab Corporation) [21, 22].

\section{Fractional factorial matrix}

A $2^{3-1}$ fractional factorial matrix was formulated using the alias structuring method (Table 1) [23, 24]. A reduced fractional factorial matrix was used for time and resource limitations, as a full factorial matrix including 4 variables would have required a total of 16 experimental runs, or 48 runs including repeats. Varying only one condition per run would only allow determination of the main effect of one parameter
Table 1 Sample labels used in the matrix study and their respective solution processing conditions

\begin{tabular}{lll}
\hline & $1.0 \mathrm{M}$ uranyl nitrate & $1.5 \mathrm{M}$ uranyl nitrate \\
\hline $1.5 \mathrm{M}$ oxalic acid & Sample S1 (direct) & Sample S3 (reverse) \\
$2 \mathrm{M}$ oxalic acid & Sample S2 (reverse) & Sample S4 (direct) \\
\hline
\end{tabular}

on the sample. However, by employing a matrix, it is possible to study both the main effect contributions and interactions with other variables on the properties of the sample. In this study, a 2-factor design was considered, each with 2 levels $(-$ and +$)$, extended to a 3 -factor matrix by algorithm. Each factor was assigned a label of $\mathrm{A}, \mathrm{B}$ and $\mathrm{C}$, with a corresponding grid of 4 combinations of high $(+1)$ and low $(-1)$ levels. Multiplication of levels from each factor gave rise to the third factor, column $\mathrm{C}$, formed as the product of $\mathrm{A} * \mathrm{~B}=\mathrm{C}$; this was the completed fractional factorial matrix. The factors and their corresponding levels were:
A. Concentration of uranyl nitrate $(1.0$ and $1.5 \mathrm{M})$
B. Concentration of oxalic acid (1.5 and $2 \mathrm{M})$
C. Strike order of reagent addition (reverse and direct)

\section{Scanning electron microscopy}

Roughly $10 \mathrm{mg}$ of each sample was lightly dusted onto a carbon adhesive tab and applied to a $12.77 \mathrm{~mm}$ aluminium stub mount. The stub was lightly tapped to remove excess loose material. SEM images were captured using a Hitachi TM3030 microscope at magnifications between $\times 800$ and $\times 4 \mathrm{k}$ at an accelerating voltage of $15 \mathrm{keV}$. Images were processed in ImageJ software.

\section{Inductively coupled plasma optical emission spectroscopy (ICP-OES)}

Concentrations of impurities were determined by ICP-OES, using a Thermo-Fisher 600iCAP spectrometer. $20 \mathrm{mg}$ of impure $\mathrm{UO}_{2} \mathrm{C}_{2} \mathrm{O}_{4} \cdot 3 \mathrm{H}_{2} \mathrm{O}$ and $\alpha-\mathrm{U}_{3} \mathrm{O}_{8}$ were each dissolved in nitric acid $(30 \mathrm{w} / \mathrm{w} \%)$ for analysis. The resultant concentrations of Fe impurity were normalised with respect to the concentration of $\mathrm{U}$ in each sample.

\section{Results}

\section{TGA-MS-DTA}

The change in mass observed by thermogravimetric analysis showed that $\mathrm{UO}_{2} \mathrm{C}_{2} \mathrm{O}_{4} \cdot 3 \mathrm{H}_{2} \mathrm{O}$ underwent four distinct phases of transformation during thermal decomposition to $900{ }^{\circ} \mathrm{C}$ (Fig. 1), summarised as: 


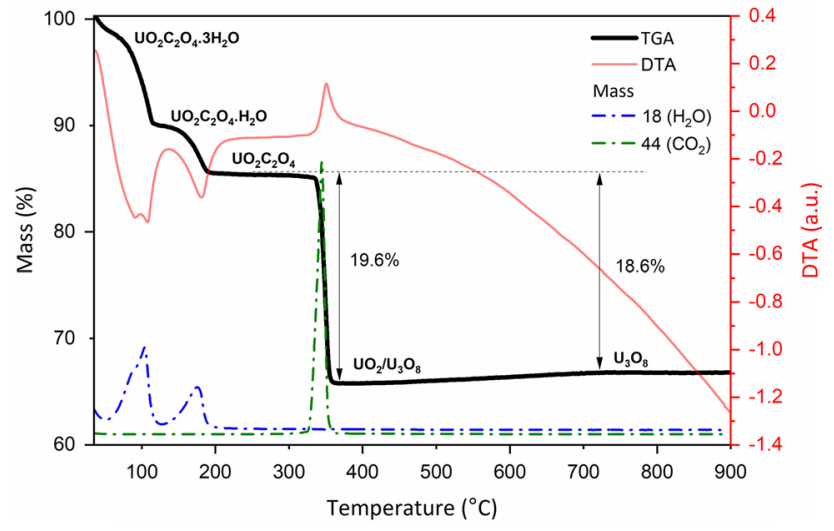

Fig. 1 TGA-MS-DTA curve for the thermal decomposition of $\mathrm{UO}_{2} \mathrm{C}_{2} \mathrm{O}_{4} \cdot 3 \mathrm{H}_{2} \mathrm{O}$ to $900{ }^{\circ} \mathrm{C}$ in a $\mathrm{N}_{2}$ atmosphere

$$
\begin{aligned}
& \mathrm{UO}_{2} \mathrm{C}_{2} \mathrm{O}_{4} \cdot 3 \mathrm{H}_{2} \mathrm{O} \rightarrow \mathrm{UO}_{2} \mathrm{C}_{2} \mathrm{O}_{4} \cdot \mathrm{H}_{2} \mathrm{O} \\
& \quad \rightarrow \mathrm{UO}_{2} \mathrm{C}_{2} \mathrm{O}_{4} \rightarrow \mathrm{UO}_{2} / \mathrm{U}_{3} \mathrm{O}_{8} \rightarrow \mathrm{U}_{3} \mathrm{O}_{8}
\end{aligned}
$$

Two endothermic troughs are present in the DTA curves at 100 and $180{ }^{\circ} \mathrm{C}$, due to the loss of $\mathrm{H}_{2} \mathrm{O}$ (Fig. 1, blue dotted line), while the exothermic peak at $380{ }^{\circ} \mathrm{C}$ occurs with the loss of $\mathrm{CO}_{2}$ (Fig. 1, green dotted line). By mass calculation, coupled with mass spectrometry, it was deduced that the trihydrate lost two $\mathrm{H}_{2} \mathrm{O}$ molecules by $100{ }^{\circ} \mathrm{C}$ (Supplementary Information, Table S1). This accounted for $9.5 \%$ weight loss, in good agreement with the theoretical $8.7 \%$. Further heating to $190{ }^{\circ} \mathrm{C}$ resulted in the emission of another molecule of $\mathrm{H}_{2} \mathrm{O}$, to form a completely dehydrated uranyl oxalate. This resulted in a further weight loss of $4.7 \%$, in good agreement with the theoretical $4.4 \%$. This phase spanned a temperature range of $145{ }^{\circ} \mathrm{C}$ before releasing $\mathrm{CO}_{2}\left(44 \mathrm{~g} \mathrm{~mol}^{-1}\right.$, green trace in Fig. 1) to form the mixed oxide; this transition was accompanied by an exothermic change in the DTA curve. A weight loss of $19.6 \%$ occurred in this step, in satisfactory agreement with the $21.4 \%$ theoretical weight loss. Until $700{ }^{\circ} \mathrm{C}$, the mixed phase gained mass, eventually forming $\mathrm{U}_{3} \mathrm{O}_{8}$. This phase change was accompanied by a weight gain of $2.7 \%$, in excellent agreement with the $2.7 \%$ calculated for the theoretical value.

\section{X-ray diffraction (XRD)}

The standard batch sample was confirmed to be monoclinic $\mathrm{P} 121 / \mathrm{c} 1 \mathrm{UO}_{2} \mathrm{C}_{2} \mathrm{O}_{4} \cdot 3 \mathrm{H}_{2} \mathrm{O}$ (Fig. 2) by XRD comparison to the Inorganic Crystal Structure Database (ICSD) [25, 26]. Reflection positions matched well against reference, however, the literature $\left(\begin{array}{lll}1 & 1 & 1\end{array}\right)$ reflection intensity was significantly greater than was observed in this experiment. To confirm this assignment, refinements were carried out using the Rietveld method (Supplementary Information, Table S2) [27]. The phase was confirmed with fitting to the reference
P121/c1 model used in the by-eye assignment, with an Rwp value of 15.50 and $\chi^{2}$ of $3.24(\mathrm{a}=5.620 \pm 0.002$ $\mathrm{b}=17.013 \pm 0.006$ and $\mathrm{c}=9.301 \pm 0.002)$. The XRD patterns of samples exposed to 150 and $250{ }^{\circ} \mathrm{C}$ were similar in reflection angle to the unheated oxalate, despite comprising fewer structural $\mathrm{H}_{2} \mathrm{O}$ molecules. A satisfactory fit was established with the same $\mathrm{UO}_{2} \mathrm{C}_{2} \mathrm{O}_{4} \cdot 3 \mathrm{H}_{2} \mathrm{O}$ model, achieving an Rwp of 25.70 and 16.75 for samples heated to 150 and $250{ }^{\circ} \mathrm{C}$, respectively. These were accompanied by values of $\chi^{2}=2.40$ and 2.50 , respectively, indicating a fit satisfactorily independent of noise effects. Peak intensity ratios varied slightly in the sample heated to $150{ }^{\circ} \mathrm{C}$, with a greater intensity in the $\left(\begin{array}{lll}0 & 4 & 1\end{array}\right)$ reflection. The sample heated to $400{ }^{\circ} \mathrm{C}$ was found to be a mixed $\mathrm{UO}_{2} / \mathrm{U}_{3} \mathrm{O}_{8}$ phase, consisting of broad reflections, indicating smaller crystallite size [28, 29]. By Rietveld analysis, it was confirmed that this was a mixed phase of $\mathrm{UO}_{2}(\mathrm{Fm} 3 \mathrm{~m}, \mathrm{a}=5.434 \pm 0.001 \AA$, 94.83\%) and $\alpha-\mathrm{U}_{3} \mathrm{O}_{8}(\mathrm{C} 2 \mathrm{~mm}, \mathrm{a}=6.490 \pm 0.007 \mathrm{~b}=11.997 \pm 0.01$ and $\mathrm{c}=4.148 \pm 0.003 \AA, 5.17 \%$ ). For the product of heating to $800{ }^{\circ} \mathrm{C}$, a pattern of single-phase $\mathrm{U}_{3} \mathrm{O}_{8}$ was obtained [30]. Significant peak splitting occurred in this pattern, confirming that the sample was the $\alpha-\mathrm{U}_{3} \mathrm{O}_{8}$ polymorph of orthorhombic $\mathrm{C} 2 \mathrm{~mm}$ symmetry $(\mathrm{a}=6.689 \pm 0.001 \mathrm{~b}=11.885 \pm 0.002$ and $\mathrm{c}=4.135 \pm 0.0006)$. This assignment was confirmed with Rietveld refinement, achieving a good fit of $R_{w p}=18.996$ and $\chi^{2}=1.44$ to the reference model [28].

\section{X-ray absorption spectroscopy (XANES and EXAFS)}

\section{XANES and EXAFS of pure samples}

The absorption edge energy, $E_{0}$, can be used to measure changes in uranium oxidation state with increasing temperature of heating, and is determined from the maximum of the normalised first derivative (Table 2). $E_{0}$ was situated at 17,184 $\pm 0.2 \mathrm{eV}$ for samples heated from 25 to $250{ }^{\circ} \mathrm{C}$, corresponding well with industrially manufactured $\mathrm{UO}_{2} \mathrm{C}_{2} \mathrm{O}_{4} \cdot 3 \mathrm{H}_{2} \mathrm{O}$ standard $(17,184.3 \mathrm{eV})$. These $E_{0}$ values correspond well to a partial charge of $\mathrm{U}(\mathrm{VI})$ in $\mathrm{UO}_{2} \mathrm{C}_{2} \mathrm{O}_{4} \cdot 3 \mathrm{H}_{2} \mathrm{O}$ and its dehydrated forms (Fig. 3) [14]. In samples heated to higher temperature, a shift in the $E_{0}$ energy from 17,184 to $17,186 \mathrm{eV}$ also occurred, confirming partial reduction to $\mathrm{U}(\mathrm{V} / \mathrm{VI})$ in $\alpha-\mathrm{U}_{3} \mathrm{O}_{8}$.

In the normalised spectra (Fig. 3), Feature A corresponds to the 'white line' at the absorption edge. The shoulder Feature $\mathrm{B}$, situated at $\sim 17,196 \mathrm{eV}$, is characteristic of uranyl bonding $\left(\mathrm{UO}_{2}\right)^{2+}$ and is present in each sample heated up to $250{ }^{\circ} \mathrm{C}$. This feature arises from multiple scattering paths along the trans-dioxo $\left(\mathrm{UO}_{2}\right)^{2+}$ cation [31,32]. In the spectra of samples heated to $400{ }^{\circ} \mathrm{C}$ and above, the shoulder feature was lost. Feature $\mathrm{C}$ was most prominent in the samples heated to lower temperatures, and corresponds to multiple scattering along the equatorial $\mathrm{U}-\mathrm{O}_{\text {eq }}$ path [32]. The feature 


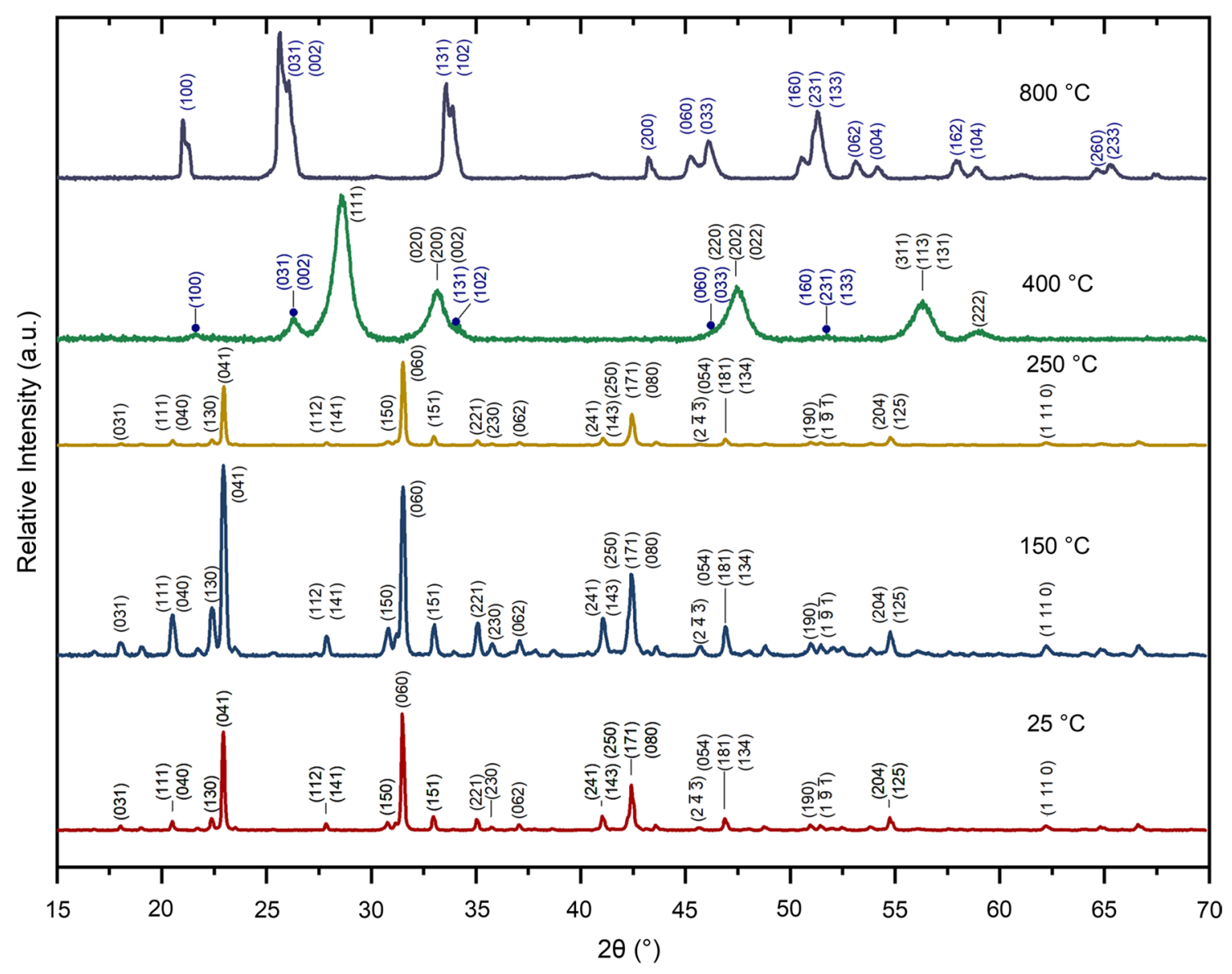

Fig. 2 XRD patterns for heat treated samples of $\mathrm{UO}_{2} \mathrm{C}_{2} \mathrm{O}_{4} \cdot 3 \mathrm{H}_{2} \mathrm{O}$. The patterns for $25-250{ }^{\circ} \mathrm{C}$ are indexed as $\mathrm{UO}_{2} \mathrm{C}_{2} \mathrm{O}_{4} \cdot 3 \mathrm{H}_{2} \mathrm{O}$. ${ }^{25}$ The pattern for $400{ }^{\circ} \mathrm{C}$ is indexed as the $\mathrm{UO}_{2} / \mathrm{U}_{3} \mathrm{O}_{8}$ mixed phase, where a blue dot denotes the $\mathrm{U}_{3} \mathrm{O}_{8}$ phase..$^{28,30}$ The pattern at $800{ }^{\circ} \mathrm{C}$ is indexed as pure $\alpha-\mathrm{U}_{3} \mathrm{O}_{8} \cdot{ }^{30}$

Table 2 Energy of features A-C.. $\mathrm{E}_{0}$ is also shown, determined as the maximum of the normalised first derivative

\begin{tabular}{llllll}
\hline Phase & Feature A $(\mathrm{eV})$ & Feature B $(\mathrm{eV})$ & Feature C (eV) & \multicolumn{2}{c}{$\begin{array}{l}\mathrm{E}_{0} \text {, First Derivative } \\
(\mathrm{eV})\end{array}$} \\
\hline $\mathrm{UO}_{2} \mathrm{C}_{2} \mathrm{O}_{4} \cdot 3 \mathrm{H}_{2} \mathrm{O}(\mathrm{STD})$ & $17,184.3$ & $17,198.6$ & $17,222.0$ & $17,180.1$ & $\mathrm{U}(\mathrm{VI})$ \\
$\mathrm{UO}_{2} \mathrm{C}_{2} \mathrm{O}_{4} \cdot 3 \mathrm{H}_{2} \mathrm{O}\left(25^{\circ} \mathrm{C}\right)$ & $17,184.1$ & $17,198.1$ & $17,221.0$ & $17,179.4$ & $\mathrm{U}(\mathrm{VI})$ \\
$\mathrm{UO}_{2} \mathrm{C}_{2} \mathrm{O}_{4} \cdot 3 \mathrm{H}_{2} \mathrm{O}\left(150^{\circ} \mathrm{C}\right)$ & $17,183.8$ & $17,197.4$ & $17,221.2$ & $17,179.7$ & $\mathrm{U}(\mathrm{VI})$ \\
$\mathrm{UO}_{2} \mathrm{C}_{2} \mathrm{O}_{4} \cdot 3 \mathrm{H}_{2} \mathrm{O}\left(250^{\circ} \mathrm{C}\right)$ & $17,184.0$ & $17,198.4$ & $17,221.3$ & $17,178.8$ & $\mathrm{U}(\mathrm{VI})$ \\
$\mathrm{UO}{ }_{2} / \alpha-\mathrm{U}_{3} \mathrm{O}_{8}\left(400^{\circ} \mathrm{C}\right)$ & $17,185.0$ & N/A & $17,227.4$ & $17,178.3$ & $\mathrm{U}(\mathrm{V} / \mathrm{VI})$ \\
$\mathrm{U}(\mathrm{V} / \mathrm{VI}) \alpha-\mathrm{U}_{3} \mathrm{O}_{8}\left(800^{\circ} \mathrm{C}\right)$ & $17,186.0$ & N/A & & &
\end{tabular}

was observed to decrease in intensity and broadened at higher temperatures.

The materials were examined in the higher energy EXAFS region. Plotted in the Fourier transform (FT) of the k-space, the photoelectron scattering profile was represented as a function of radial distance from the absorber (Supplementary Information, Tables S3 and 4). From 25 to $250{ }^{\circ} \mathrm{C}$, little difference was found between the FTs of these samples, each consisting of three major shells situated at $1.38,1.78$ and $1.99 \AA$. To further investigate and compare the structures of the $\mathrm{UO}_{2} \mathrm{C}_{2} \mathrm{O}_{4} \cdot 3 \mathrm{H}_{2} \mathrm{O}$ with the anyhdrate, the EXAFS FTs of the 25 and $250{ }^{\circ} \mathrm{C}$ samples were fitted to a standard $\mathrm{UO}_{2} \mathrm{C}_{2} \mathrm{O}_{4} \cdot 3 \mathrm{H}_{2} \mathrm{O}$ structure (Fig. 4) [25]. A k-range of 3-15 and R-range of 1-4.5 was used for the fits. Both were fitted well with $\mathrm{UO}_{2} \mathrm{C}_{2} \mathrm{O}_{4} \cdot 3 \mathrm{H}_{2} \mathrm{O}$, each with an $R$-factor no greater than 0.022 . Each fit included a path representative of the uranyl cation $\left(\mathrm{U}-\mathrm{O} 1_{\mathrm{yl}}\right.$, Supplementary Information, Figure S1), confirming the 

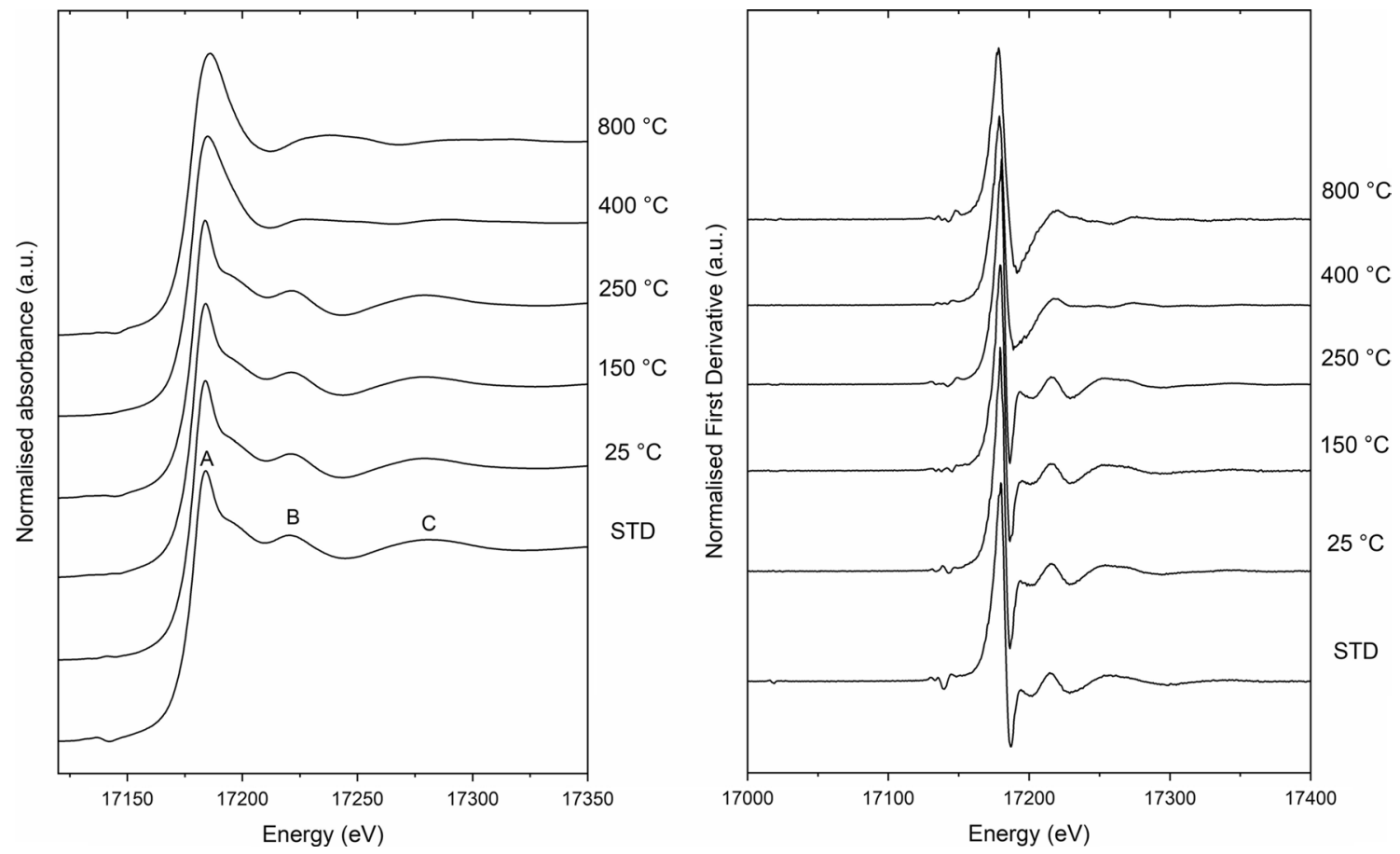

Fig. 3 Normalised XANES absorption spectrum (left) and normalised first derivative (right) for heat treated samples of uranyl oxalate
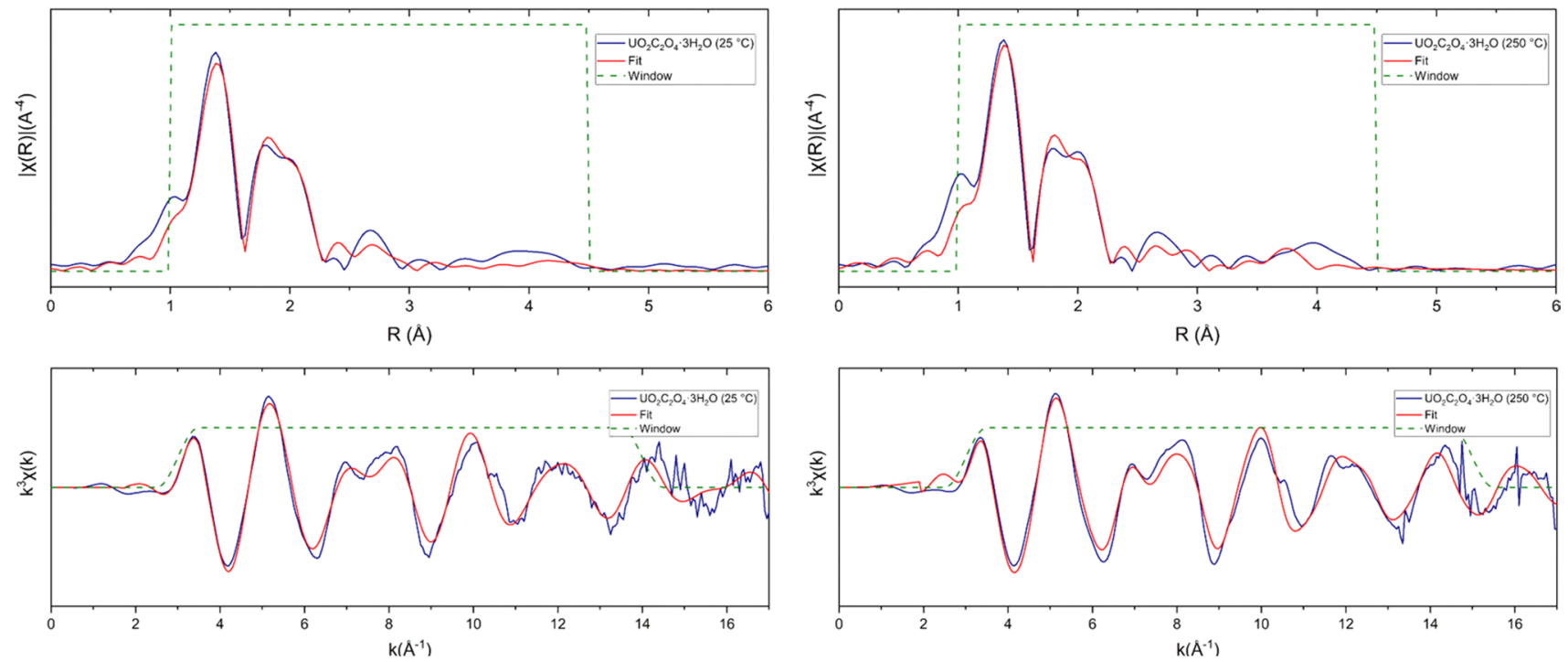

Fig. 4 Fourier transforms (top) of k3-weighted spectra (bottom) $\left[\mathrm{FT} \mathrm{k}{ }^{3} \mathrm{X}(\mathrm{k})\right]$ of uranyl oxalate at $25^{\circ} \mathrm{C}$ (left) and $250{ }^{\circ} \mathrm{C}$ (right)

observation of Feature B in XANES analysis. Additionally, the $\mathrm{U}-\mathrm{O} 3_{\text {eq }}$ and $\mathrm{U}-\mathrm{O} 4_{\text {aq }}$ paths was retained in each fit, which correspond to an equatorially bound $\mathrm{H}_{2} \mathrm{O}$ group and interstitial $\mathrm{H}_{2} \mathrm{O}$ molecules, respectively. For confirmation, the same methodology was applied to the sample heated to $150{ }^{\circ} \mathrm{C}$, also fitting well to $\mathrm{UO}_{2} \mathrm{C}_{2} \mathrm{O}_{4} \cdot 3 \mathrm{H}_{2} \mathrm{O}$ (Supplementary Information, Figure S2). The sample heated to $400{ }^{\circ} \mathrm{C}$ was fitted with two uranium absorber sites as a mixture of $\mathrm{UO}_{2}$ and $\alpha-\mathrm{U}_{3} \mathrm{O}_{8}$, while the sample heated to $800{ }^{\circ} \mathrm{C}$ was fitted as pure $\alpha-\mathrm{U}_{3} \mathrm{O}_{8}$ (both found in Supplementary Information, Figure S3).

\section{XANES and EXAFS of Fe impurity}

Table 3 shows the ICP-OES calculated concentration (ppm) of $\mathrm{Fe}$ impurity incorporated into the $\mathrm{UO}_{2} \mathrm{C}_{2} \mathrm{O}_{4} \cdot 3 \mathrm{H}_{2} \mathrm{O}$ during 
Table 3 ICP-OES analysis of Fe concentration ( $\mathrm{ppm})$ for uranyl oxalate and $\alpha-\mathrm{U}_{3} \mathrm{O}_{8}$ samples
Sample (calcination temperature)

Impurity Impurity concentration (in
sample, ppm)
Standard deviation $( \pm$ ppm)

3.46

$\mathrm{UO}_{2} \mathrm{C}_{2} \mathrm{O}_{4} \cdot 3 \mathrm{H}_{2} \mathrm{O}\left(25^{\circ} \mathrm{C}\right)$

$\mathrm{Fe}$

108.45

2.44

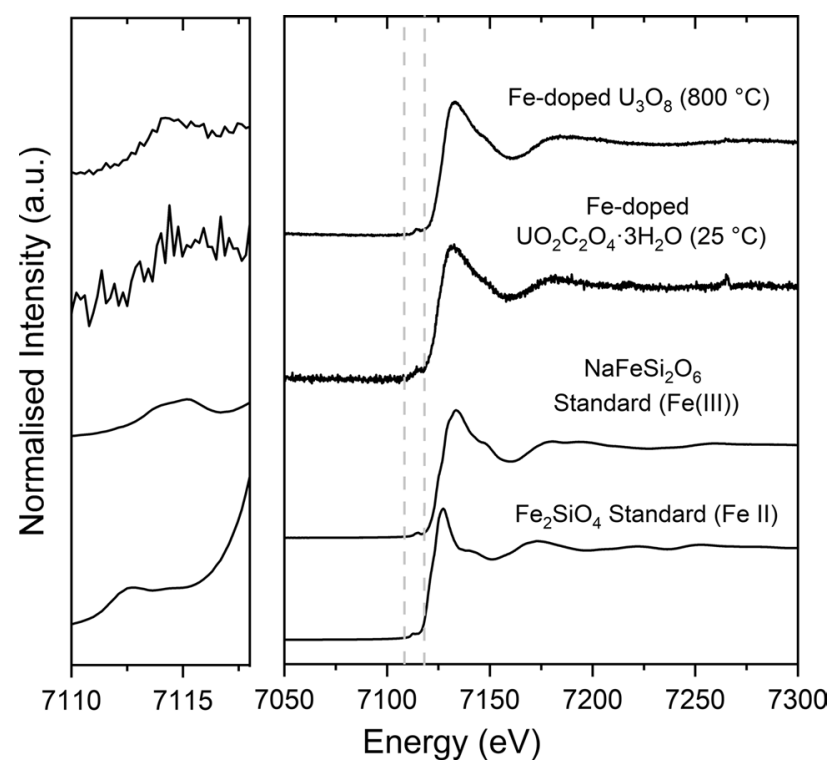

Fig. 5 XANES spectra for Fe doped uranyl oxalate samples at 25 and $800{ }^{\circ} \mathrm{C}$, with reference to standards (right). A dashed grey box highlights the energy range within which the pre-edge feature is found, which is magnified (left) precipitation. The concentration of Fe impurity in these samples was realistic for back-end fuel cycle samples [18]. Concentrations of $\mathrm{Fe}$ were normalised to the concentration of $\mathrm{U}$ present in each sample.

The XANES spectra of the Fe absorber atom is shown in Fig. 5. A strong absorption peak was observed with a weak shoulder feature situated at higher energy. The absorption peak was preceded by a weak pre-edge feature at $7114 \mathrm{eV}$ in both spectra. The maximum of the absorption edge was situated at $7133 \mathrm{eV}$ for both the 25 and $800{ }^{\circ} \mathrm{C}$ samples. The peak absorption energies of $\mathrm{Fe}_{2} \mathrm{SiO}_{4}$ (Fe II) and $\mathrm{NaFeSi}_{2} \mathrm{O}_{6}$ (Fe III) were used to compare the Fe oxidation state; the oxalate samples corresponded closest with $\mathrm{NaFeSi}_{2} \mathrm{O}_{6}(\mathrm{Fe}$ III).

The FT of the $\mathrm{k}^{3}$-weighted spectrum provides an insight to the local atomic environment of the Fe absorber atom. The $\mathrm{k}^{3}$-weighted spectrum for this sample was noisy beyond $8 \mathrm{k}(\AA)^{-1}$, so a small window between 2.5 and $7.5 \AA^{-1}$ was used for the fit. A good fit of standard $\mathrm{Fe}_{2} \mathrm{O}_{3}$ to the $25^{\circ} \mathrm{C} \mathrm{FT}$ (Fig. 6a), $R=0.011$ ) implies that the Fe impurity is bonded to oxygen atoms in a similar manner to this crystal structure [33]. This result was unexpected, as the reaction of $\mathrm{Fe}\left(\mathrm{NO}_{3}\right)_{3} \cdot 9 \mathrm{H}_{2} \mathrm{O}$ with $\mathrm{C}_{2} \mathrm{H}_{2} \mathrm{O}_{4}$ would normally yield ferric
Fig. 6 Fourier transforms $(\mathbf{a}-\mathbf{c})$ of $\mathrm{k}^{3}$-weighted spectra and [FT $\mathrm{k}^{3} \mathrm{X}(\mathrm{k})(\mathbf{d}-\mathbf{f})$. a and $\mathbf{d}$ correspond to Fe impurity in the sample heated to $25^{\circ} \mathrm{C}$, fitted with paths from the reference $\mathrm{Fe}_{2} \mathrm{O}_{3}$ model. $\mathbf{b}$ and $\mathbf{e}$ are $\mathrm{Fe}$ impurity in $\mathrm{U}_{3} \mathrm{O}_{8}\left(800{ }^{\circ} \mathrm{C}\right)$, fitted with the reference $\mathrm{Fe}_{2} \mathrm{O}_{3}$ model. $\mathbf{c}$ and $\mathbf{f}$ correspond to $\mathrm{Fe}$ impurity in $\mathrm{U}_{3} \mathrm{O}_{8}\left(800{ }^{\circ} \mathrm{C}\right)$ over a k-range between 3 and $10 \AA^{-1}$
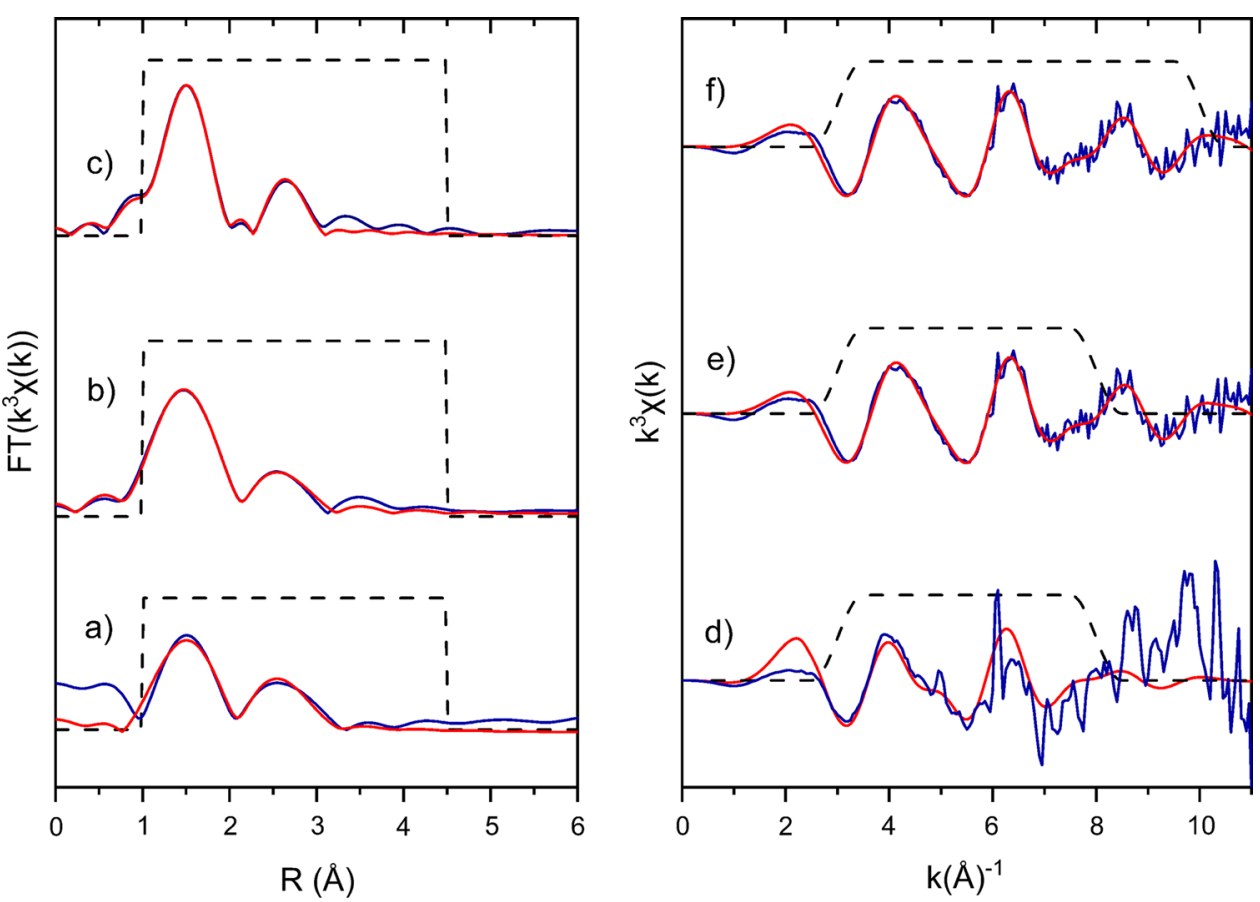
oxalate $\left(\mathrm{C}_{6} \mathrm{Fe}_{2} \mathrm{O}_{12}\right)$. However, when the same data was fitted with a reference $\mathrm{C}_{6} \mathrm{Fe}_{2} \mathrm{O}_{12} \mathrm{CIF}$, the fit was unsatisfactory. While the visual fit seemed good, some negative thermal parameters were returned, in addition to high $E_{0}$ and $\Delta R$ values, suggesting that the model for $\mathrm{C}_{6} \mathrm{Fe}_{2} \mathrm{O}_{12}$ was an incorrect solution to this data (Supplementary Information, Table S6 and Figure S5).

The same k-window was also used in the fit of the sample heated to $800{ }^{\circ} \mathrm{C}$, to yield a good fit of the $\mathrm{Fe}_{2} \mathrm{O}_{3}$ standard to the data $(\mathrm{R}=0.009)$. As the $\mathrm{k}^{3}$-weighted spectrum was not as noisy for this sample, and to demonstrate the effect of $\mathrm{k}$-window on the FT, another fit was produced, with the same R-window (1-4.5 $\AA$ ). The full set of parameters and standard crystal structure of $\mathrm{Fe}_{2} \mathrm{O}_{3}$ can be found in the Supplementary Information, in Table S5 and Figure S4, respectively. To determine whether Fe was incorporated into the structure of $\mathrm{U}_{3} \mathrm{O}_{8}$ by substitution of $\mathrm{U}$ sites, this data was also fitted with a reference $\mathrm{U}_{3} \mathrm{O}_{8}$ dataset (Supplementary Information, Table S6 and Figure S5); the U core was instead replaced with $\mathrm{Fe}$ in the corresponding FEFF calculation. This returned a fit of seemingly reasonable parameters, apart from a high value of $E_{0}(-13.53 \pm 3.89 \mathrm{eV})$ and an unsatisfactory $R$-factor $(R=0.088)$. For this reason, the model was rejected as a solution to this structure.

\section{Hygroscopicity of $\mathrm{UO}_{2} \mathrm{C}_{2} \mathrm{O}_{4}$}

A sample of $\mathrm{UO}_{2} \mathrm{C}_{2} \mathrm{O}_{4} \cdot 3 \mathrm{H}_{2} \mathrm{O}$ was heated to $250{ }^{\circ} \mathrm{C}$ in a nitrogen atmosphere to form the anhydrous oxalate, $\mathrm{UO}_{2} \mathrm{C}_{2} \mathrm{O}_{4}$. Based on results from XRD and EXAFS fitting, it was expected that the anhydrous phase would completely rehydrate to form $\mathrm{UO}_{2} \mathrm{C}_{2} \mathrm{O}_{4} \cdot 3 \mathrm{H}_{2} \mathrm{O}$. This was confirmed by measuring the change in mass of the heat treated sample over time, while it was exposed to air for 20 min (Fig. 7).
Following air exposure, the sample was heat treated again, this time with TGA-MS-DTA (Fig. 7). This analysis gave rise to an identical TGA curve to $\mathrm{UO}_{2} \mathrm{C}_{2} \mathrm{O}_{4} \cdot 3 \mathrm{H}_{2} \mathrm{O}$ (Fig. 1), and emitted gaseous $\mathrm{H}_{2} \mathrm{O}\left(18 \mathrm{~g} \mathrm{~mol}^{-1}\right)$ was detected by $\mathrm{MS}$ at the same temperatures as in the thermal decomposition of $\mathrm{UO}_{2} \mathrm{C}_{2} \mathrm{O}_{4} \cdot 3 \mathrm{H}_{2} \mathrm{O}$. No $\mathrm{CO}_{2}$ gas was detected during these transitions, as expected. A DTA curve, similar to that seen in Fig. 1, also accompanied these results. Thus, the $\mathrm{UO}_{2} \mathrm{C}_{2} \mathrm{O}_{4}$ phase was shown to be hygroscopic at room temperature.

\section{Matrix study: morphology of $\mathrm{UO}_{2} \mathrm{C}_{2} \mathrm{O}_{4} \cdot 3 \mathrm{H}_{2} \mathrm{O}$}

A $2^{3-1}$ fractional factorial matrix of processing parameters was employed for the precipitation of $\mathrm{UO}_{2} \mathrm{C}_{2} \mathrm{O}_{4} \cdot 3 \mathrm{H}_{2} \mathrm{O}$. The experiment was repeated three times to ensure reliability of parameter interactions, with particle and agglomerate morphology examined by SEM. However, it was found from these repeated experiments that the morphology of $\mathrm{UO}_{2} \mathrm{C}_{2} \mathrm{O}_{4} \cdot 3 \mathrm{H}_{2} \mathrm{O}$ is not easily replicated, despite the use of identical solution processing conditions. Hence, the micrographs obtained for each set of parameters over the three experiments differed on each run. This indicated that there may be parameters, beyond those studied in this matrix, that affected the morphology of solution grown $\mathrm{UO}_{2} \mathrm{C}_{2} \mathrm{O}_{4} \cdot 3 \mathrm{H}_{2} \mathrm{O}$. Nonetheless, particle sizes were calculated manually from 20 particles per image, for a representative range. A manual selection 'line' tool was used to set boundaries of particle edges prior to area calculation, as the majority of particles were non-circular or square. For Run 1 only, samples S5e-S8e were included for comparison of particle size and agglomeration beyond the matrix. Particle morphology was described by the terminology set out in the nuclear forensic lexicon reported by Tamasi et al. (Supplementary Information, Tables S7 and 8) [34]. Three types of particle

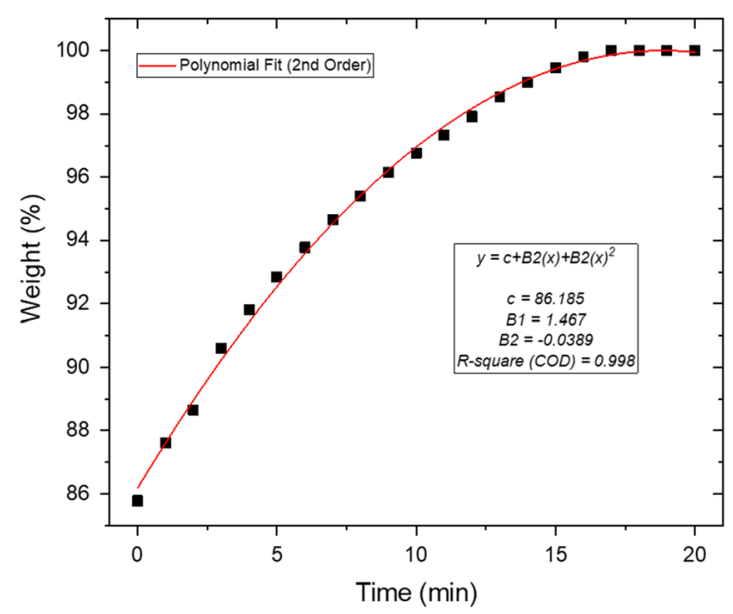

Fig. 7 Weight change of $\mathrm{UO}_{2} \mathrm{C}_{2} \mathrm{O}_{4}$ as a percentage of initial weight of $\mathrm{UO}_{2} \mathrm{C}_{2} \mathrm{O}_{4} \cdot 3 \mathrm{H}_{2} \mathrm{O}$, with respect to time (left). The TGA-MS-DTA of the same material is shown (right) after cooling to room tempera-

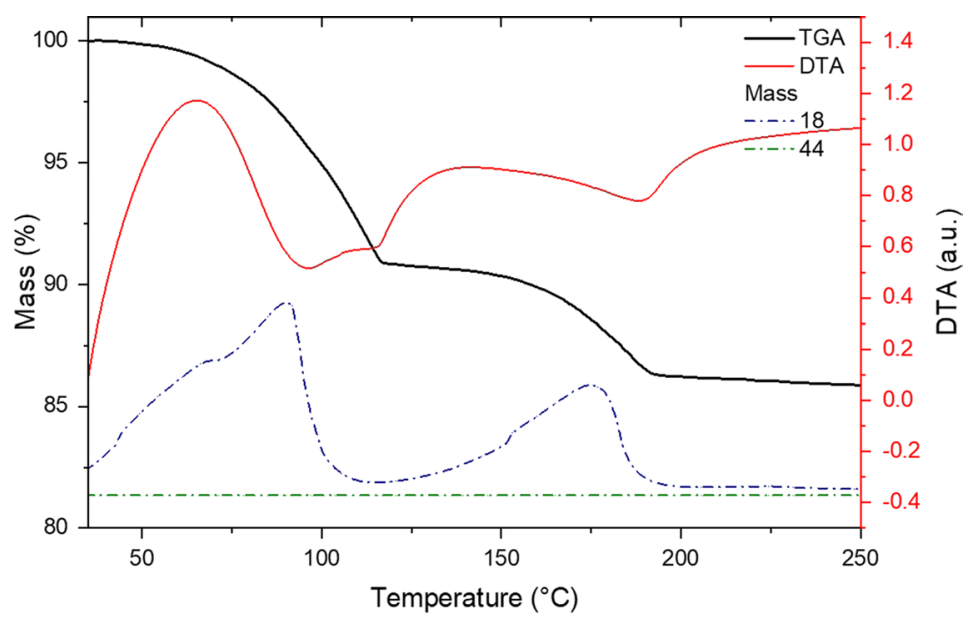

ture and exposure to air for $20 \mathrm{~min}$; this corresponds to the thermal decomposition of $\mathrm{UO}_{2} \mathrm{C}_{2} \mathrm{O}_{4} \cdot 3 \mathrm{H}_{2} \mathrm{O}$ 


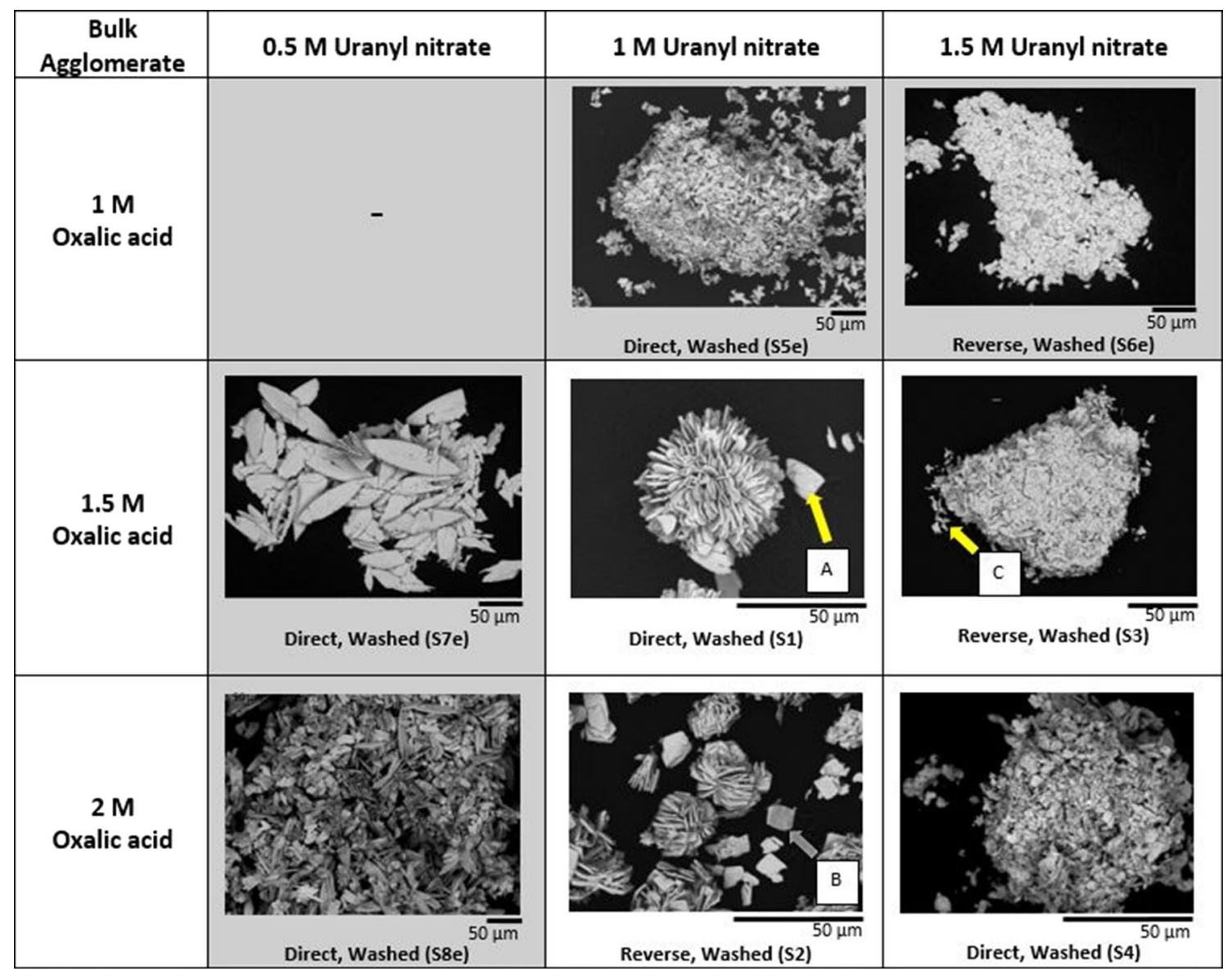

Fig. 8 SEM images of bulk agglomerates from a matrix of solution processing parameters for uranyl oxalate, including variations in uranyl nitrate and oxalic acid concentration and reagent strike order

morphology were consistently observed throughout this study; lenticular blades, square plates and mixed fines. The lenticular particles, as seen in sample S1 (Feature A, Figs. 8 and 9), were $\leq 8 \mu \mathrm{m}$ in diameter, and up to $140 \mu \mathrm{m}^{2}$ in area. In all three matrix runs that they occurred, they had agglomerated spherically into a rosette formation, usually between 50 and $60 \mu \mathrm{m}$ in diameter. An exception was noted for samples S7e and S8e, in which the much larger lenticular particles formed conglomerates. It should be noted that conglomerates comprise particles of heterogeneous size and morphology, while homogeneous particles form agglomerates. Square plates (Feature B) were present in sample S2 (and S1/S2 for Run 2, S3 for Run 3), which were up to $11 \mu \mathrm{m}$ in diameter and $75 \mu \mathrm{m}^{2}$ in area. Similarly, in all experimental runs that these occurred, the particles were arranged into round 'paddle wheel' agglomerates of 20-30 $\mu \mathrm{m}$ diameter. A range of smaller fines and plates were obtained with other conditions, often between 0.1 and $5 \mu \mathrm{m}$ in diameter and $0.3-14 \mu \mathrm{m}^{2}$ in area. These had clustered, in every case, to large conglomerates of fines (Feature $\mathrm{C}$ ).
Heating the samples from Run 1 to form $\mathrm{U}_{3} \mathrm{O}_{8}\left(800^{\circ} \mathrm{C}\right)$ did not affect the morphology of the bulk material, irrespective of particle morphology in the precursor oxalate (Figs. 10, 11, 12). Particles thinned significantly, with some cracking present on the surfaces (Feature D) and splitting through the centre of the grain (Feature E). Particle edges also appeared to be more angular compared to precursors. Despite these changes, the bulk agglomerate morphology was generally retained, unaffected by thermal processing. Agglomerates were, therefore, indistinguishable from the precursor material by their morphology alone. It is noted, however, that the rosette agglomerates of sample S1 were between 40 and $50 \mu \mathrm{m}$ in diameter, smaller than in the precursor material. Individual particle size was generally smaller in $\mathrm{U}_{3} \mathrm{O}_{8}$ samples, apart from in sample $\mathrm{S} 4$, which were larger in diameter $(2.5-5.5 \mu \mathrm{m})$ and area $\left(10-28 \mu \mathrm{m}^{2}\right)$. In other samples, the diameter decreased by $<8 \mu \mathrm{m}$, while the decrease in area was somewhat more significant. This was most obvious in the particle area of sample S2, where the range dropped to $13-58 \mu \mathrm{m}^{2}$ from $35-75 \mu \mathrm{m}^{2}$ in the 


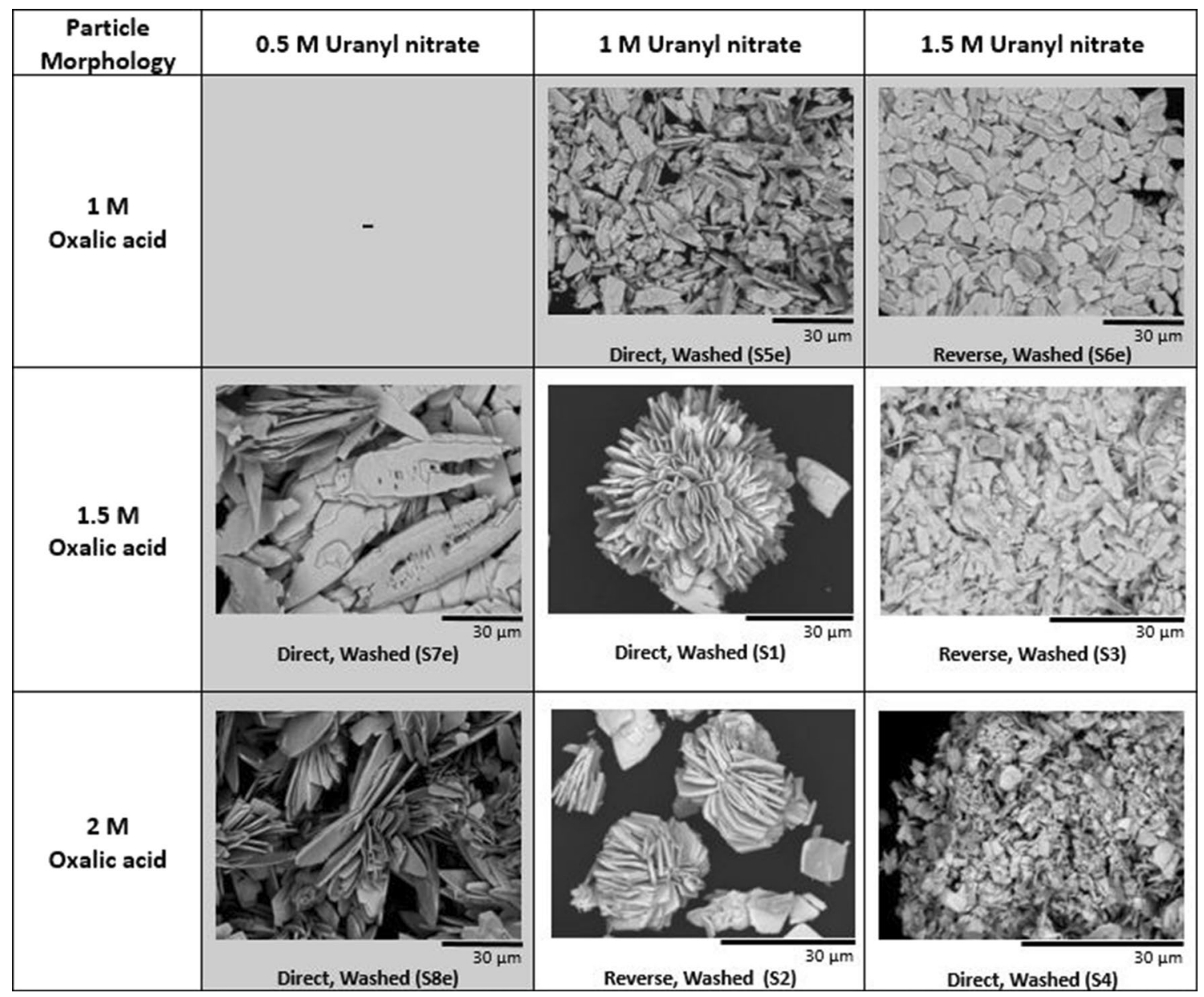

Fig. 9 SEM images of particles from matrix of solution processing parameters for uranyl oxalate, including variations in uranyl nitrate and oxalic acid concentration and reagent strike order

precursor. The particle area was indeterminate for sample S1, due to the well agglomerated nature of the material, giving rise to fewer loose particles for area analysis.

Samples produced with the addition of $\mathrm{Fe}\left(\mathrm{NO}_{3}\right)_{3} \cdot 9 \mathrm{H}_{2} \mathrm{O}_{(\mathrm{aq})}$ during precipitation consisted of fine, platy particles, generally conglomerated into larger bulk particles. These conglomerates, while spherical and sub-rounded on the edges, appeared to be randomly dispersed on the surface due to the nature of static forces of interaction between the particle fines. Despite their random dispersion, it was possible to qualitatively examine particles and determine particle size from a representative image. The sample doped with Fe consisted of particles between 5 and $10 \mu \mathrm{m}$ in diameter, larger in size compared to the control oxalate sample, in which they were $2.5-5 \mu \mathrm{m}$ in diameter. The particle morphology of the control sample can be described similarly to sample S3 (Supplementary Information, Table S7) and the Fe doped to sample S1. Particles were similar in their 'blocky' morphology for both conditions. When heated, the particles of the impure oxalate showed surface fracturing. At $400{ }^{\circ} \mathrm{C}$, these generally exhibited a low number of cracks relative to samples heated at higher temperatures. At $600{ }^{\circ} \mathrm{C}$, a greater number of cracks were noticeable on the surfaces, also presenting with rougher, more angular edges. At $800{ }^{\circ} \mathrm{C}$, particles were noticeably thinner with cracks propagating across the width of the lens. This was not dissimilar to the effects of heating pure $\mathrm{UO}_{2} \mathrm{C}_{2} \mathrm{O}_{4} \cdot 3 \mathrm{H}_{2} \mathrm{O}$ to the same temperature, where particles also revealed surface cracks (Fig. 10).

\section{Discussion}

\section{TGA and XRD}

By coupling the calculated mass loss from TGA with XRD patterns of heat-quenched samples, it was possible to confirm the existence of crystalline phases at particular temperature intervals. The DTA curve troughs at 100 and $180{ }^{\circ} \mathrm{C}$ are attributed to the breakage of hydrogen bonds between $\mathrm{H}_{2} \mathrm{O}$ and bonded $\mathrm{O}$ atoms [35]. The crystal structure of all uranyl 
Fig. 10 SEM images of $\mathrm{U}_{3} \mathrm{O}_{8}$ particles from matrix of solution processing parameters for uranyl oxalate. Variations in uranyl nitrate and oxalic acid concentration, and reagent strike order, in the solution processing of uranyl oxalate precursor are shown

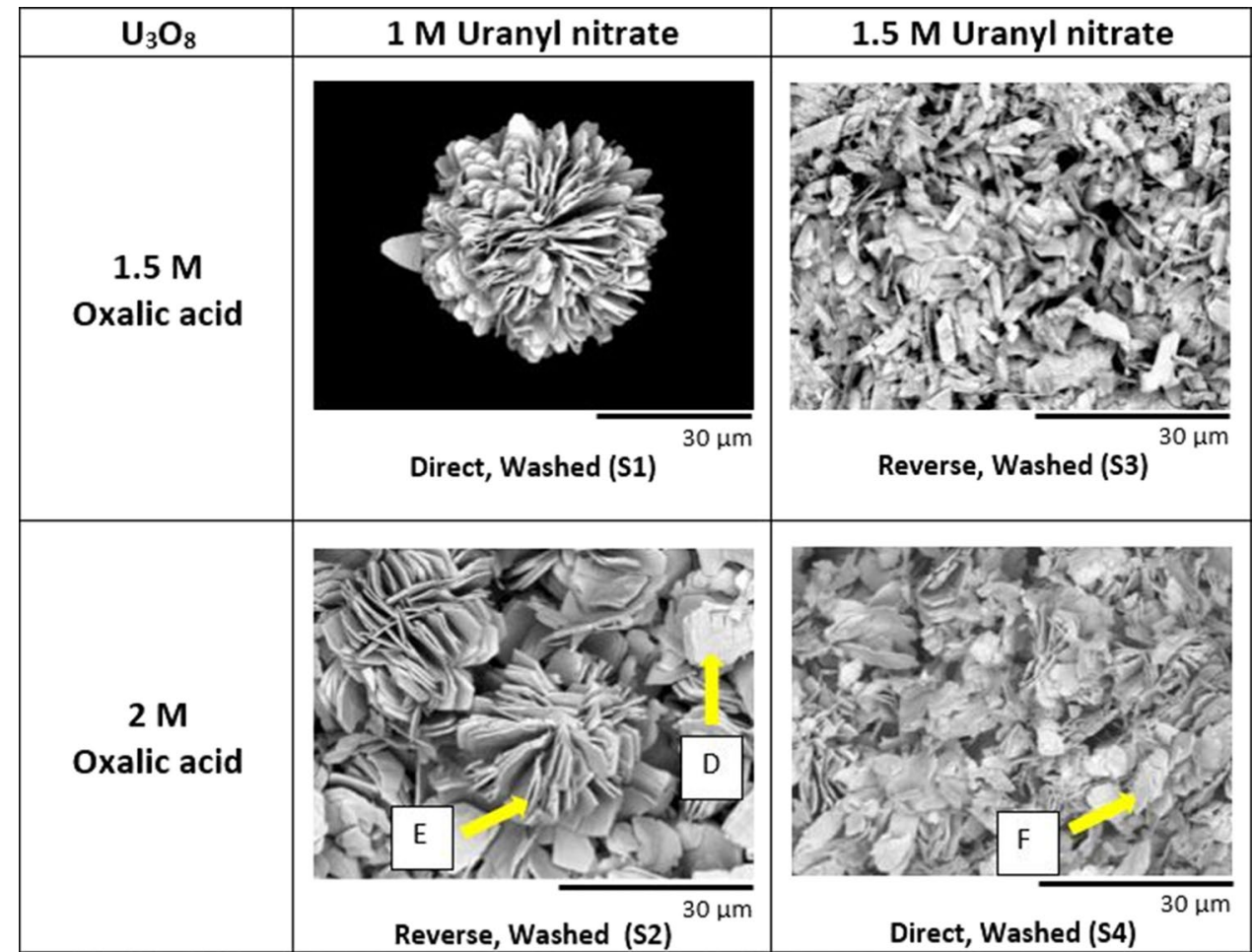

oxalate hydrates is $\mathrm{P} 121 / \mathrm{n} 1$, confirmed with reference to the ICSD database [25]. The ratio of reflection intensities observed in the presented XRD patterns of uranyl oxalates differed significantly from those previously reported, including those of the industrial standard. This was most likely a result of preferred orientation, as reflection angles were still in agreement despite the difference in intensities. It was considered unusual that all oxalates exhibited a similar XRD pattern, as in similar mechanisms, dehydration can affect the crystal structure such that a distinguishable XRD pattern is obtained [36-38]. This result supports the argument that $\mathrm{UO}_{2} \mathrm{C}_{2} \mathrm{O}_{4}$ is hygroscopic, absorbing $\mathrm{H}_{2} \mathrm{O}$ with brief exposure to air prior to $\mathrm{XRD}$ analysis and reforming the trihydrate oxalate. Applied to the field of nuclear forensics, XRD provides confirmation of the existence of uranyl oxalate, but not necessarily the extent of hydration.

The mixed phase $\left(400{ }^{\circ} \mathrm{C}\right)$ consisted of $\mathrm{UO}_{2}$ in cubic symmetry $\mathrm{F} \mathrm{m}-3 \mathrm{~m}$, and $\alpha-\mathrm{U}_{3} \mathrm{O}_{8}$ in orthorhombic $\mathrm{C} 2 \mathrm{~mm}$ symmetry. This polymorph is the most stable form of $\mathrm{U}_{3} \mathrm{O}_{8}$ [39]. The exothermic peak in the DTA curve before this temperature is attributed to the formation of $\mathrm{U}-\mathrm{O}$ bonds in the mixed oxide, which outweighs the endothermic breaking of $\mathrm{CO}-\mathrm{U}$ bonds. The removal of $\mathrm{CO}_{2}$ units from the anhydrous oxalate should theoretically leave behind pure $\mathrm{UO}_{2}$. Instead, the mixed phase is formed due to the relatively greater thermal stability of $\mathrm{U}_{3} \mathrm{O}_{8}$ [40]. The mixed phase gradually oxidises to pure $\alpha-\mathrm{U}_{3} \mathrm{O}_{8}$, which would probably form more rapidly under an oxidising atmosphere rather than nitrogen.

\section{X-ray absorption spectroscopy}

\section{XANES}

It was confirmed by XANES that uranyl oxalate contains uranium in the U(VI) oxidation state, with $E_{0}$ situated at $17,184 \pm 0.2 \mathrm{eV}$ [14]. Samples that were heated to 400 and $800{ }^{\circ} \mathrm{C}$ exhibited a lower energy $E_{0}$ than the samples heated to lower temperatures. As partial atomic charge decreases, electron screening of core-hole effects increases which results in destabilisation of electron core levels. This effect is accompanied by a shift in $E_{0}$ to lower energy, as was observed in Fig. 3, indicating that the mixed phase oxide $\left(400{ }^{\circ} \mathrm{C}\right)$ contains uranium atoms in a lower oxidation state than the oxalates. This is expected with the presence of both $\mathrm{UO}_{2}$ and $\mathrm{U}_{3} \mathrm{O}_{8}$ in the sample (U(IV) and $\mathrm{U}(\mathrm{V} / \mathrm{VI})$, respectively). The shoulder feature seen in the oxalate samples is lost at higher temperatures, suggesting that the mixed phase and $\mathrm{U}_{3} \mathrm{O}_{8}$ samples do not contain a uranyl group $\left(\mathrm{UO}_{2}\right)^{2+}$.

The spectra of all uranyl oxalate species $\left(25-50{ }^{\circ} \mathrm{C}\right)$ were identical with no variation between the different states of hydration. From this, it is suggested that XANES analysis would not be useful in the field for differentiating between the hydration states of uranyl oxalate. Additionally, the XANES spectra of this compound are very similar to those obtained for other uranium compounds, particularly $\mathrm{UO}_{2}$ and $\mathrm{UO}_{2}\left(\mathrm{NO}_{3}\right)_{2}$ [41]. To this extent, XANES is perhaps a useful tool to identify the presence of a U(VI) uranyl oxide and its 

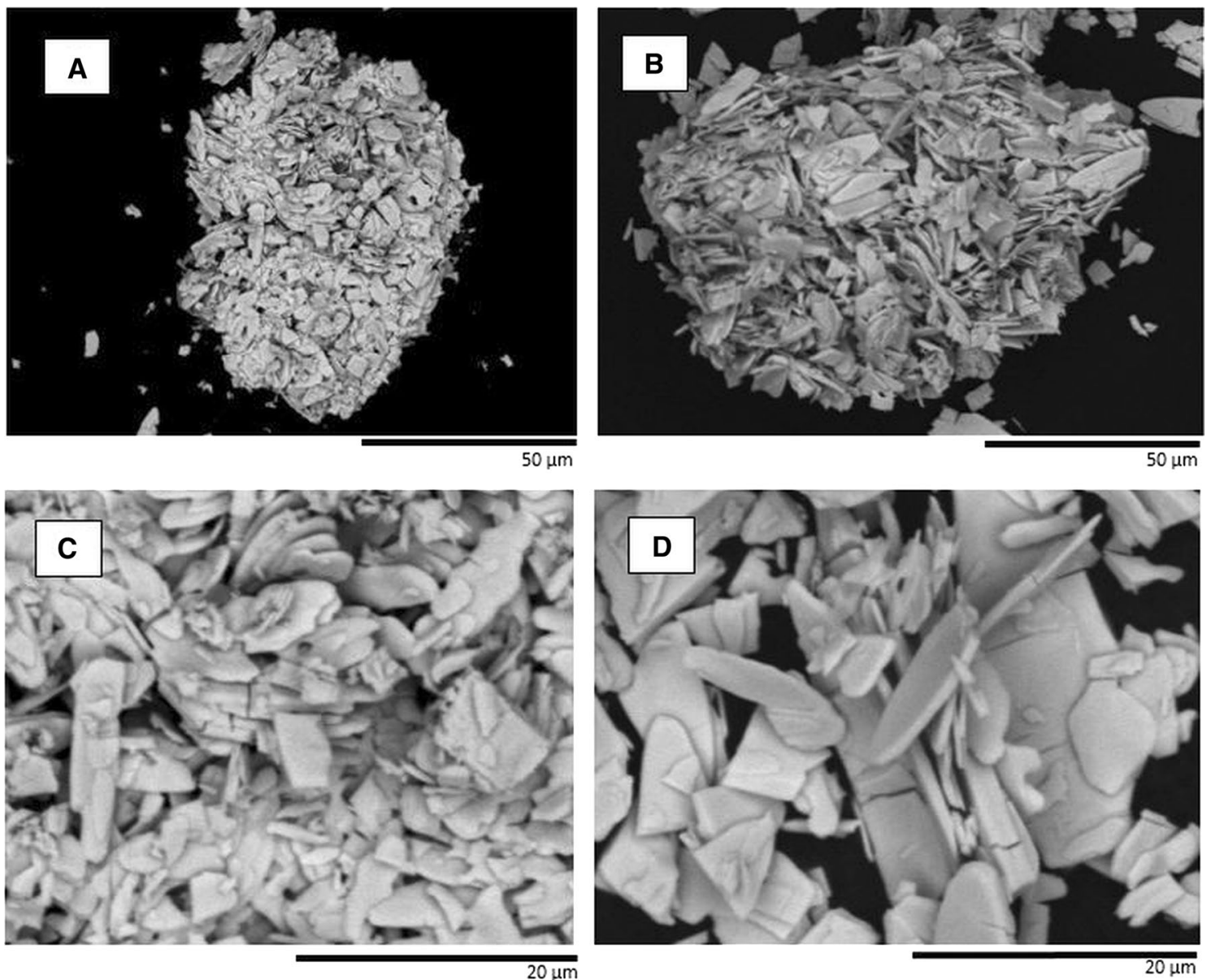

Fig. 11 SEM images of a uranyl oxalate control and $\mathbf{b}$ Fe doped uranyl oxalate agglomerates. Magnifications of individual particles are shown respectively in $\mathbf{c}$ and $\mathbf{d}$
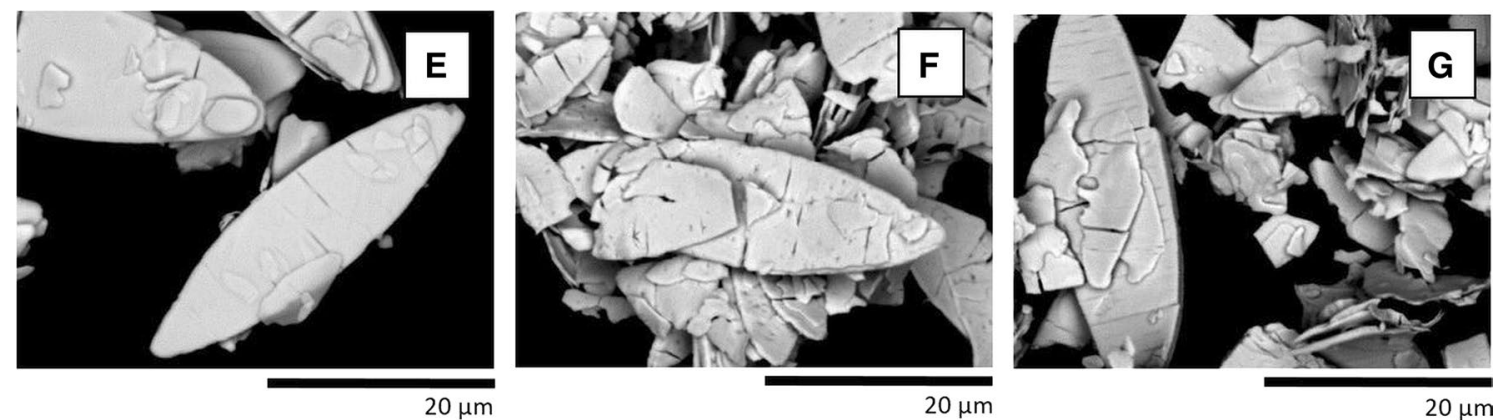

Fig. 12 Heat treated samples of Fe doped uranyl oxalate to e 400, f 600 and $\mathbf{g} 800{ }^{\circ} \mathrm{C}$

local atomic environment, but may prove less reliable in the identification of the compound itself.

\section{EXAFS}

To further investigate the hydration of the oxalate species, EXAFS analysis was carried out on the spectra of the 25 and $250{ }^{\circ} \mathrm{C}$ samples (trihydrate and anhydrate, respectively).
Both EXAFS data were initially fitted with only the $\mathrm{U}-\mathrm{O} 1_{\mathrm{yl}}$, $\mathrm{O} 2_{\text {eq }}, \mathrm{O} 3$ and $\mathrm{C} 1$ scattering paths, but unphysical, negative values for $\sigma^{2}$ were returned after fitting. By including the $\mathrm{U}-\mathrm{O} 4_{\mathrm{aq}}$ path, which is attributed to scattering between $\mathrm{U}$ and interstitial $\mathrm{H}_{2} \mathrm{O}$, the fit returned physically sound parameters with a satisfactory $R$-factor $(0.022)$. The good fit with standard $\mathrm{UO}_{2} \mathrm{C}_{2} \mathrm{O}_{4} \cdot 3 \mathrm{H}_{2} \mathrm{O}$ data suggests that the sample heated to $250{ }^{\circ} \mathrm{C}$ was, in fact, a completely hydrated oxalate. 
Attempting to fit the $250{ }^{\circ} \mathrm{C}$ data without the $\mathrm{U}-\mathrm{O} 22_{\text {eq }}$ and $\mathrm{O} 4$ aq paths returned a visually less satisfactory fit with a lower R-factor (0.025). As such, it is likely that the dehydrated uranyl oxalate species are hygroscopic. This would also explain the almost identical XRD patterns observed for the hydrated and anhydrous uranyl oxalate samples, discussed in "TGA and XRD" section. Interestingly, water was seemingly still absorbed by these samples despite their storage in air-tight plastic containers over a period of two weeks. Thus, at room temperature in air, it is believed that uranyl oxalate exists in the trihydrate form. The mixed oxide obtained from heating to $400{ }^{\circ} \mathrm{C}$ had a satisfactory fit with $\mathrm{UO}_{2}$ and $\alpha-\mathrm{U}_{3} \mathrm{O}_{8}(\mathrm{R}$-factor $=0.031)$, utilising two values of $E_{0}$ to account for the multi-absorber site structure. Pure $\alpha-\mathrm{U}_{3} \mathrm{O}_{8}$ from heating to $800{ }^{\circ} \mathrm{C}$ fitted well to crystallographic data $(\mathrm{R}$-factor $=0.016)$.

\section{Fe impurity}

The energy of $E_{0}(7133 \mathrm{eV})$ for the Fe XANES spectra is evidence of the $\mathrm{Fe}(\mathrm{III})$ oxidation state, as shown when compared with the standard $\mathrm{NaFeSi}_{2} \mathrm{O}_{6}$. This is supported by analysis of the pre-edge feature, centred at $7114 \mathrm{eV}$, which corresponds to previous assignments of Fe(III) compounds at an average position of $7113.1 \pm 0.2 \mathrm{eV}$, in addition to the reference compounds used here [42]. While an absolute assignment for the compound cannot usually be made from XANES, the energies and spectral features correspond well with the literature, particularly hematite $\left(\mathrm{Fe}_{2} \mathrm{O}_{3}\right)$ and $\mathrm{C}_{6} \mathrm{Fe}_{2} \mathrm{O}_{12}[43,44]$. It has been noted, however, that the spectra of these compounds often exhibit a pre-maximum shoulder feature at around $7127 \mathrm{eV}$, which was not present in our data [45]. Interestingly, the XANES spectra of both the room temperature $\left(25^{\circ} \mathrm{C}\right)$ sample and that heated to $800^{\circ} \mathrm{C}$ were almost identical. As the XANES features of various ferrous oxides and oxalates are generally distinguishable, it seems possible that there was no change in the composition of the Fe environment during heat treatment.

The EXAFS FTs of the two Fe impurities were nearly identical, further indicating that the Fe environment was unaltered during heat treatment. The k-space and FT of both samples most closely resemble that exhibited by ferrihydrite $\left(\mathrm{Fe}_{2} \mathrm{O}_{3} \cdot 0.5 \mathrm{H}_{2} \mathrm{O}\right)$ [45]; the XANES spectrum of ferrihydrite also does not contain a pre-maximum shoulder feature, as was noted for the samples examined here. It was not possible to fit EXAFS data to ferrihydrite due to its partial occupancy, but select scattering paths from anhydrous $\mathrm{Fe}_{2} \mathrm{O}_{3}$ provided a suitable fit to the data. Fitting with a reference $\mathrm{C}_{6} \mathrm{Fe}_{2} \mathrm{O}_{12}$ model persistently returned unsatisfactory fits. Thus, the $\mathrm{Fe}$ absorber atom is situated within the proximity of $6 \mathrm{O}$ atoms and another $3 \mathrm{Fe}$ atoms, without scattering contributions from $\mathrm{C}$ atoms. In this case, the atoms are arranged in an irregular octahedral formation. The mechanism for $\mathrm{Fe}_{2} \mathrm{O}_{3}$ formation from $\mathrm{Fe}\left(\mathrm{NO}_{3}\right)_{3} \cdot 9 \mathrm{H}_{2} \mathrm{O}$ and $\mathrm{C}_{2} \mathrm{H}_{2} \mathrm{O}_{4}$ is not clear, as $\mathrm{C}_{6} \mathrm{Fe}_{2} \mathrm{O}_{12}$ is expected to form as a result of this reaction. Hence, following the results of EXAFS fitting, it is hypothesised that $\mathrm{Fe}$ is not situated within the oxalate structure as a substitution defect, but is perhaps more likely to be an interstitial impurity closely surrounded by six $\mathrm{O}$ atoms. Attempts to fit the sample heated to $800{ }^{\circ} \mathrm{C}$ with a modified Fe-core $\alpha-\mathrm{U}_{3} \mathrm{O}_{8}$ model was unsuccessful. This again suggests that Fe was not incorporated into the structure of this compound, and supports the hypothesis that this impurity was not present as a substitution defect. Further investigations should be conducted to determine the type of defect assumed by the Fe impurity in both compounds. This could extend to further XAS experiments and HR-XRD, also with a higher concentration of $\mathrm{Fe}$ nitrate. DFT simulations incorporating $\mathrm{Fe}$ into the crystal structure of $\mathrm{UO}_{2} \mathrm{C}_{2} \mathrm{O}_{4} \cdot 3 \mathrm{H}_{2} \mathrm{O}$ may also elucidate the environment in which it resides within this compound.

As a nuclear forensic tool for examining impurity content, XANES analysis could be utilised to confirm the presence of a suspected impurity, such as Fe, in the bulk compound. However, in this study, the analysis of Fe impurity was not particularly well suited to detecting the thermal processing history of uranyl oxalate. The Fe compound underwent no discernible transformation with heating to $800{ }^{\circ} \mathrm{C}$, except for exhibiting a somewhat stronger shoulder feature. Future work should include investigations into the changes in Fe XANES, in samples heated to intermediate temperatures (in the range $25-800{ }^{\circ} \mathrm{C}$ ). This would help to clarify the effect of thermal processing on the Fe impurity.

\section{Hygroscopicity of $\mathrm{UO}_{2} \mathrm{C}_{2} \mathrm{O}_{4}$}

The investigation of hygroscopicity of the anhydrous phase was warranted following results from XRD and EXAFS fitting. The uptake of atmospheric $\mathrm{H}_{2} \mathrm{O}$ by $\mathrm{UO}_{2} \mathrm{C}_{2} \mathrm{O}_{4}$ was shown to be rapid, with complete hydration occurring in under $20 \mathrm{~min}$, confirming the hypothesis that the anhydrous phase is hygroscopic. The rate of hydration was fastest in the first 5 min of exposure to air, slowing with time, as the equilibrium state of the material is reached. The full rehydration of this compound to $\mathrm{UO}_{2} \mathrm{C}_{2} \mathrm{O}_{4} \cdot 3 \mathrm{H}_{2} \mathrm{O}$ suggests that hygroscopicity extends beyond loose chemical bonding; both the interstitial and molecularly bonded $\mathrm{H}_{2} \mathrm{O}$ groups must be present in the atomic structure after exposure to air. From a nuclear forensic perspective, this finding implies that it would be unlikely to intercept a sample of anhydrous $\mathrm{UO}_{2} \mathrm{C}_{2} \mathrm{O}_{4}$, given the highly driven formation of the hydrated phase minutes after calcination. However, immediate storage of this sample in an inert atmosphere and suitably air-tight container may preserve the anhydrous compound, and thus requires further investigation. 


\section{SEM analysis}

\section{Matrix study: morphology of uranyl oxalate}

The particle morphology of $\mathrm{UO}_{2} \mathrm{C}_{2} \mathrm{O}_{4} \cdot 3 \mathrm{H}_{2} \mathrm{O}$ varied in each experimental repeat, even when the same conditions were employed. Hence, it was not possible to reliably ascribe a particular set of processing conditions to the formation of a certain particle morphology. However, three types of particular morphology were observed, as discussed here: these were small fines, lenticular blades and square plates.

The growth of lenticular bladed particles probably occurs simultaneously with the growth of the rosette agglomerate; the constituent particles are generally equally sized, radiating in a well organised formation. A mechanism for particle growth would involve the clustering of a nucleus of smaller particles during the early stages of precipitation, eventually each growing along preferred axes with time [46, 47]. In some instances, the particle overgrows, and the rosette is broken apart. This appears to have been the case for sample S7e, where blades possess a prominent hole through the bottom half of the particle, presumably formed during their fracturing from the rosette. Such an instance of overgrowth is attributed to the low uranyl nitrate concentration $(0.5 \mathrm{M})$ used in this reaction. The concentration of uranyl nitrate in solution, therefore, appears to be important to the growth of particles. A higher uranyl nitrate concentration gave rise to smaller particles in the majority of experiments, sample S4 of run 3 (Supplementary Information, Figure S3) being the exception to this. This trend corresponds with previous findings from similar experiments; both the precipitation and particle growth rates are increased at higher uranyl nitrate concentrations, the main contributing factor to smaller particle size [3].

The formation of the paddle wheel agglomerates of sample S2 were likely formed in a similar manner to that of the rosettes. This formation is particularly prevalent with particles of squared edges, as opposed to the spherical nature of the rosette formed by bladed particles. It therefore appears that the selection of agglomerate type is dependent on the morphology, and thus, the arranging geometry, of the particles composing it.

Fine particles always gave rise to a large conglomerate in this study. Unlike the agglomerates, the morphology of the conglomerates was not a direct result of solution processing conditions. Rather, they were formed during the filtration steps following precipitation. A large suction force formed a solid precipitate cake on the filter paper, upon which the fines clustered. With further drying, the evaporation of residual solvent left solid bridges between particles. The particles were also subjected to high attractive forces of interaction, with a high surface to volume ratio aiding in their static binding.
The prevalence of thinner, cracked particles in the higher temperature $\mathrm{U}_{3} \mathrm{O}_{8}$ material likely arose from the loss of gaseous $\mathrm{H}_{2} \mathrm{O}$ and $\mathrm{CO}_{2}$ during thermal decomposition. As the temperature increases, particles are structurally compromised as the gases find a way to escape the particle. The formation of angular edges would also result from dehydration in this case. Thermal expansion during heating, and contraction from cooling, would also give rise to the deformations seen in these particles. The observed reduction in particle size corresponds with previous studies, which have demonstrated that uranium oxide particle size decreases with increasing temperature [7]. However, particle size may again increase above a threshold temperature, as sintering effects occur. This is a plausible explanation for the increase in particle size for thermally treated sample S4, where SEM images show the appearance of sintering between particles (Fig. 10, Feature F). It is known that particle morphology can influence the ability of particles to sinter at high temperature [48]. In this case, sintering has occurred between heterogeneous, flat particles, whereas more homogeneous particles remained well separated.

In nuclear forensics, the signatures of size and morphological features in $\mathrm{U}_{3} \mathrm{O}_{8}$ would provide evidence as to the thermal processing of $\mathrm{UO}_{2} \mathrm{C}_{2} \mathrm{O}_{4} \cdot 3 \mathrm{H}_{2} \mathrm{O}$. Interestingly, the morphological signatures in the bulk agglomerates, and conglomerates, are retained in the heat treated sample, as are the general forms of the constituent particles. This is a significant finding in the context of nuclear forensic application, as these particles of $\mathrm{U}_{3} \mathrm{O}_{8}$ may be traced back to their uranyl oxalate precursor. These particles of $\mathrm{U}_{3} \mathrm{O}_{8}$ can be differentiated, therefore, from those obtained by the thermal decomposition of other precursors (such as studtite), so that the provenance of an intercepted $\mathrm{U}_{3} \mathrm{O}_{8}$ material may be more accurately determined in the field [2, 7, 34].

\section{Fe impurity}

Particles in the uranyl oxalate control sample were smaller than those produced with Fe doping. The explanation for this depends on the type of defect assumed by the Fe impurity. In the case of a substitution defect, the difference in charge resulting from the replacement of U(VI) with Fe(III) would be compensated for by the creation of $\mathrm{O}^{2-}$ vacancies [16]. These anionic vacancies would allow for greater ion movement through the structure, hence, promoting particle growth. On the other hand, an interstitial type defect would potentially expand the lattice parameters of the unit cell. With increasing temperature, more fracturing was present on the surface of particles. This was likely due to a combination of gas expulsion prior to $400{ }^{\circ} \mathrm{C}$ and thermal expansion and contraction thereafter. The increasing number of cracks with temperature indicates that thermally induced particle fracturing could be a reliable nuclear forensic signature of the thermal processing history of uranyl oxalate compounds. 


\section{Conclusion}

A selection of nuclear forensic signatures of $\mathrm{UO}_{2} \mathrm{C}_{2} \mathrm{O}_{4} \cdot 3 \mathrm{H}_{2} \mathrm{O}$ and its products of thermal decomposition were established.

It was found by TGA-MS-DTA that $\mathrm{UO}_{2} \mathrm{C}_{2} \mathrm{O}_{4} \cdot 3 \mathrm{H}_{2} \mathrm{O}$ undergoes four distinct phases of transformation from room temperature to $900{ }^{\circ} \mathrm{C}$, accompanied by the evolution of gaseous $\mathrm{H}_{2} \mathrm{O}$ and $\mathrm{CO}_{2}$. The $\mathrm{UO}_{2} \mathrm{C}_{2} \mathrm{O}_{4} \cdot 3 \mathrm{H}_{2} \mathrm{O}$ phase was confirmed by ex situ XRD analysis, and possesses the P121/ c1 symmetry. The ratio of peak intensities in these XRD patterns differed significantly from the literature, likely as a result of preferred orientation effects. The subsequent mixed phase oxide formed from heating to $400{ }^{\circ} \mathrm{C}$ was calculated to be $\mathrm{UO}_{2}(\mathrm{Fm} 3 \mathrm{~m}, 94.83 \%)$ and $\alpha-\mathrm{U}_{3} \mathrm{O}_{8}(\mathrm{C} 2 \mathrm{~mm}, 5.17 \%)$, while samples heated to $800{ }^{\circ} \mathrm{C}$ were confirmed to be pure $\alpha-\mathrm{U}_{3} \mathrm{O}_{8}$.

Interestingly, the samples heated to 150 and $250{ }^{\circ} \mathrm{C}$ exhibited an XRD pattern almost identical to that of $\mathrm{UO}_{2} \mathrm{C}_{2} \mathrm{O}_{4} \cdot 3 \mathrm{H}_{2} \mathrm{O}$, despite TGA-MS-DTA analysis showing the loss of structural $\mathrm{H}_{2} \mathrm{O}$ at these temperatures. Further investigation by TGA-DTA-MS and weight analysis showed that the anhydrous $\mathrm{UO}_{2} \mathrm{C}_{2} \mathrm{O}_{4}$ is hygroscopic, completely rehydrating in under $20 \mathrm{~min}$ in air. This was further confirmed in EXAFS analysis, as a satisfactory fit to these samples was only obtained when including $\mathrm{U}-\mathrm{O}_{\mathrm{H} 2 \mathrm{O}}$ scattering paths in the model. Thus, the seemingly identical XRD patterns are likely a result of this rehydration; further studies by high temperature XRD (HT-XRD) should be conducted in situ, to establish the crystal structure of the dehydrated phases. It is considered unlikely that dehydrated uranyl oxalates would be encountered in nuclear forensic scenarios, given their rapid hygroscopicity in air. However, if produced and stored under an inert atmosphere, it is hypothesised that these samples could be isolated, and this warrants further investigation in the field.

From XANES analysis, it was found that $\mathrm{UO}_{2} \mathrm{C}_{2} \mathrm{O}_{4} \cdot 3 \mathrm{H}_{2} \mathrm{O}$ contains the $\mathrm{U}(\mathrm{VI})$ oxidation state from its $E_{0}$ value of $17,184 \pm 0.2 \mathrm{eV} . E_{0}$ values shift to lower energy with increasing temperature, corresponding to $\mathrm{U}(\mathrm{IV}, \mathrm{V} / \mathrm{VI})$ in the mixed oxide $\left(400{ }^{\circ} \mathrm{C}\right)$ and $\mathrm{U}(\mathrm{V} / \mathrm{VI})$ in $\alpha-\mathrm{U}_{3} \mathrm{O}_{8}$. Shoulder peaks (as seen in Feature B) situated at $\sim 17,196 \mathrm{eV}$ indicate the presence of uranyl $\left(\mathrm{UO}_{2}\right)^{2+}$ bonding in the samples heated up to $250^{\circ} \mathrm{C}$. In EXAFS analysis, good fits were obtained between standard crystallographic data and the FTs of all samples, with $R$-factors below 0.022 in each case.

The morphologies of $\mathrm{UO}_{2} \mathrm{C}_{2} \mathrm{O}_{4} \cdot 3 \mathrm{H}_{2} \mathrm{O}$ varied upon each experimental repeat of the matrix, suggesting that intricate control of external parameters, such as atmospheric temperature, is required to reproduce morphological signatures. Particles of three general morphologies were obtained from precipitation: small fines, lenticular blades and square plates. In the bulk sample, blades and plates formed agglomerates while fines tended to form conglomerates. Lenticular blades $\left(95-140 \mu \mathrm{m}^{2}\right)$ were arranged into spherical rosettes
(50-60 $\mu \mathrm{m}$ diameter), which appeared to radiate from a central nucleation point. Square plates $\left(35-75 \mu \mathrm{m}^{2}\right)$ arranged as 'paddle wheel' agglomerates (20-30 $\mu$ m diameter) which also appeared to radiate around a central nucleation point. Conglomerates formed by fine particles $\left(0.3-30 \mu \mathrm{m}^{2}\right)$ were larger in diameter $(80-100 \mu \mathrm{m})$, and generally lacked a definitive form. Due to the variation of morphology between experimental runs, it was not possible to ascribe any particular solution processing conditions to a certain particle morphology. Further work on establishing the effect of external parameters (such as atmospheric conditions) on the sample morphology of precipitated $\mathrm{UO}_{2} \mathrm{C}_{2} \mathrm{O}_{4} \cdot 3 \mathrm{H}_{2} \mathrm{O}$ would be beneficial in this area.

Fe impurity $(108.45 \pm 3.46 \mathrm{ppm})$ within $\mathrm{UO}_{2} \mathrm{C}_{2} \mathrm{O}_{4} \cdot 3 \mathrm{H}_{2} \mathrm{O}$, also retained in $\alpha-\mathrm{U}_{3} \mathrm{O}_{8}(103.45 \pm 2.44 \mathrm{ppm})$, was detectable by XAS. In the XANES region, pre-edge features at $\sim 7114 \mathrm{eV}$ corresponded to the those found in $\mathrm{NaFeSi}_{2} \mathrm{O}_{6}$, the $\mathrm{Fe}$ (III) standard used. Additionally, the $E_{0}$ value of $7133 \mathrm{eV}$ matched that of the Fe(III) standard, further confirming its oxidation state. In the EXAFS region, good fits (below $R$-factor $=0.011$ ) were obtained between standard crystallographic data of $\mathrm{Fe}_{2} \mathrm{O}_{3}$ and FTs of the impurity. Despite the good EXAFS fit, however, it is unclear as to how $\mathrm{Fe}_{2} \mathrm{O}_{3}$ would form from the reagents used. In this case, it is probable that $\mathrm{Fe}$ would be interstitially incorporated into the structure of $\mathrm{UO}_{2} \mathrm{C}_{2} \mathrm{O}_{4} \cdot 3 \mathrm{H}_{2} \mathrm{O}$, surrounded by six $\mathrm{O}$ atoms in a manner similar to that found in $\mathrm{Fe}_{2} \mathrm{O}_{3}$. To confirm this, further investigation would be beneficial to determine the type of defect assumed by the Fe impurity. This could extend to further XAS experiments and HR-XRD with a higher concentration of Fe nitrate. DFT simulations incorporating $\mathrm{Fe}$ into the crystal structure of $\mathrm{UO}_{2} \mathrm{C}_{2} \mathrm{O}_{4} \cdot 3 \mathrm{H}_{2} \mathrm{O}$ may also elucidate the environment in which it resides within this compound. The FT of the EXAFS for both the 25 and $800{ }^{\circ} \mathrm{C}$ samples were almost identical, suggesting that the atomic environment surrounding $\mathrm{Fe}$ is unchanged during heat treatment. These findings are significant in the context of nuclear forensics, as the detection and analysis of trace impurity in the bulk sample could aid in the provenance of intercepted materials.

The morphologies of $\mathrm{UO}_{2} \mathrm{C}_{2} \mathrm{O}_{4} \cdot 3 \mathrm{H}_{2} \mathrm{O}$ varied upon each experimental repeat of the matrix, suggesting that intricate control (such as atmospheric temperature) is required to reproduce morphological signatures. Particles of three general morphologies were obtained from precipitation: small fines, lenticular blades and square plates. In the bulk sample, blades and plates formed agglomerates while fines tended to form conglomerates. Lenticular blades were arranged into spherical rosettes, which appeared to radiate from a central nucleation point. Square plates arranged as 'paddle wheel' agglomerates which also appeared to radiate around a central nucleation point. Conglomerates formed by 
fine particles were larger in diameter, and generally lacked a definitive form.

When heated to $800{ }^{\circ} \mathrm{C}$, particle size is generally smaller. Some particle areas increased, however, believed to be a result of sintering effects above an undefined threshold temperature; determination of this temperature would be useful information from further studies. It is posited that particle shape and size may control the threshold sintering temperature. The edges of particles were angular after thermal treatment, and also appeared to be thinner. Surface cracks were also visible. These features are attributed to the escape of gaseous $\mathrm{H}_{2} \mathrm{O}$ and $\mathrm{CO}_{2}$ during thermal decomposition, as shown by MS analysis, which induce thermal strain on the particle. The bulk agglomerate and conglomerate morphologies were retained from the precursor oxalate material, as in the constituent particles. This is significant in nuclear forensics, as the origin of this $\mathrm{U}_{3} \mathrm{O}_{8}$ powder can be traced back to the oxalate precursor by these morphological signatures. It is also possible to differentiate this powder from $\mathrm{U}_{3} \mathrm{O}_{8}$ produced by the thermal decomposition of other precursors, such as studtite.

$\mathrm{UO}_{2} \mathrm{C}_{2} \mathrm{O}_{4} \cdot 3 \mathrm{H}_{2} \mathrm{O}$ doped with $\mathrm{Fe}$ impurity exhibited larger particles than in non-doped samples. This may be explained by charge compensation effects between U(VI) and Fe(III) substitutions, or potentially expanded lattice parameters in the case of interstitial defection. This should be confirmed by further investigation by XAS and XRD. Surface cracks, particle thinning and edge angulation were also observed after heating to high temperature, similar to the non-doped samples. Hence, particle morphology may aid in identifying thermal processing of intercepted $\alpha-\mathrm{U}_{3} \mathrm{O}_{8}$ (pure and impure) samples, to help establish the provenance and processing history of this material.

Supplementary information The online version of this article (https:// doi.org/10.1007/s10967-020-07538-2) contains supplementary material, which is available to authorized users.

Acknowledgements This research utilised the HADES/MIDAS facility at the University of Sheffield established with financial support from EPSRC and BEIS, under grant EP/T011424/1 [49]. Our gratitude is extended to Dr. Gianantonio Cibin at The Diamond Lightsource for assisting with the collection of XAS measurements on the B18 beamline. We would like to acknowledge Dr. Colleen Mann for conducting ICP-OES experiments. (C) British Crown Owned Copyright 2020/AWE. Published with the permission of the Controller of Her Britannic Majesty's Stationery Office.

Open Access This article is licensed under a Creative Commons Attribution 4.0 International License, which permits use, sharing, adaptation, distribution and reproduction in any medium or format, as long as you give appropriate credit to the original author(s) and the source, provide a link to the Creative Commons licence, and indicate if changes were made. The images or other third party material in this article are included in the article's Creative Commons licence, unless indicated otherwise in a credit line to the material. If material is not included in the article's Creative Commons licence and your intended use is not permitted by statutory regulation or exceeds the permitted use, you will need to obtain permission directly from the copyright holder. To view a copy of this licence, visit http://creativecommons.org/licenses/by/4.0/.

\section{References}

1. US NRC (2017) Review of spent fuel reprocessing and associated accident phenomena

2. Tamasi A, Cash L, Tyler Mullen W, Ross A, Ruggiero C, Scott B, Wagner G, Walensky J, Zerkle S, Wilkerson M (2016) Comparison of morphologies of a uranyl peroxide precursor and calcination products. J Radioanal Nucl Chem 309:827-832. https://doi. org/10.1007/s10967-016-4692-x

3. Kim K, Hyun J, Lee K, Lee E, Lee K, Song K, Moon J (2011) Effects of the different conditions of uranyl and hydrogen peroxide solutions on the behavior of the uranium peroxide precipitation. J Hazard Mater 193:52-58. https://doi.org/10.1016/j.jhazm at.2011.07.032

4. Guo X, Wu D, Xu H, Burns P, Navrotsky A (2016) Thermodynamic studies of studtite thermal decomposition pathways via amorphous intermediates $\mathrm{UO}_{3}, \mathrm{U}_{2} \mathrm{O}_{7}$, and $\mathrm{UO}_{4}$. $\mathrm{J}$ Nucl Mater 478:158-163. https://doi.org/10.1016/j.jnucmat.2016.06.014

5. Ho D, Jones A, Goulermas J, Turner P, Varga Z, Fongaro L, Fanghänel T, Mayer K (2015) Raman spectroscopy of uranium compounds and the use of multivariate analysis for visualization and classification. Forensic Sci Int 251:61-68. https://doi. org/10.1016/j.forsciint.2015.03.002

6. Thomas R, Rivenet M, Berrier E, de Waele I, Arab M, Amaraggi D, Morel B, Abraham F (2017) Thermal decomposition of $\left(\mathrm{UO}_{2}\right) \mathrm{O}_{2}\left(\mathrm{H}_{2} \mathrm{O}\right)_{2} \cdot 2 \mathrm{H}_{2} \mathrm{O}$ : Influence on structure, microstructure and hydrofluorination. J Nucl Mater 483:149-157. https://doi. org/10.1016/j.jnucmat.2016.11.009

7. Schwerdt I, Brenkmann A, Martinson S, Albrecht B, Heffernan S, Klosterman M, Kirkham T, Tasdizen T, McDonald L IV (2018) Nuclear proliferomics: A new field of study to identify signatures of nuclear materials as demonstrated on alpha$\mathrm{UO}_{3}$. Talanta 186:433-444. https://doi.org/10.1016/j.talan ta.2018.04.092

8. Tel H, Bülbül M, Eral M, Altaş Y (1999) Preparation and characterization of uranyl oxalate powders. J Nucl Mater 275:146-150. https://doi.org/10.1016/S0022-3115(99)00119-1

9. McCombie C, Isaacs T (2010) The key role of the back-end in the nuclear fuel cycle. Daedalus 139:32-43

10. International Atomic Energy Agency (2018) Development of a national nuclear forensics library: a system for the identification of nuclear or other radioactive material out of regulatory control. IAEA, Vienna

11. International Atomic Energy Agency (2015) Nuclear forensics in support of investigations

12. Buttress G, Hughes M (1968) The thermal decomposition of uranyl(VI) oxalate. J Chem Soc A Inorg Phys Theor. https://doi. org/10.1039/J19680001985

13. Dollimore D, Jones L, Nicklin T, Spooner P (1973) Thermal decomposition of oxalates. Part 13-Surface area changes in the thermal decomposition of uranyl oxalate. J Chem Soc, Faraday Trans 69:1827. https://doi.org/10.1039/F19736901827

14. Crean D, Corkhill C, Nicholls T, Tappero R, Collins J, Hyatt N (2015) Expanding the nuclear forensic toolkit: chemical profiling of uranium ore concentrate particles by synchrotron X-ray microanalysis. RSC Adv 5:87908-87918. https://doi.org/10.1039/ C5RA14963K

15. Orr R, Sims H, Taylor R (2015) A review of plutonium oxalate decomposition reactions and effects of decomposition temperature 
on the surface area of the plutonium dioxide product. J Nucl Mater 465:756-773. https://doi.org/10.1016/j.jnucmat.2015.06.058

16. Mondal O, Pal M, Singh R, Sen D, Mazumder S, Pal M (2015) Influence of doping on crystal growth, structure and optical properties of nanocrystalline $\mathrm{CaTiO}_{3}$ : a case study using small-angle neutron scattering. J Appl Crystallogr 48:836-843. https://doi. org/10.1107/S1600576715006664

17. Sangwal K (1993) Effect of impurities on the processes of crystal growth. J Appl Crystallogr 128:1236-1244. https://doi. org/10.1016/S0022-0248(07)80129-1

18. IAEA (2007) Management of reprocessed uranium: current status and future prospects

19. Baldev R, Kamachi Mudali U, Vijayalakshmi M, Mathew M, Bhaduri A, Chellapandi P, Venugopal S, Sundar C, Rao B, Venkatraman B (2013) Adv Mater Res 794:3-25. https://doi.org/10.4028/ www.scientific.net/AMR.794.3

20. Thompson N, Gilbert M, Hyatt N (n.d.) Nuclear forensic signatures of studtite and $\alpha-\mathrm{UO}_{3}$ from a matrix of solution processing parameters. J Nucl Mater, Unpublished results

21. Ravel B, Newville M (2005) Athena, artemis, hephaestus: data analysis for $\mathrm{x}$-ray absorption spectroscopy using IFEFFIT. J Synchrotron Radiat 12:537-541. https://doi.org/10.1107/S090904950 5012719

22. Origin(Pro), Version (2017) OriginLab corporation. Origin(Pro), Version, Northampton

23. Antony J (2003) Design of experiments for engineers and scientists. Butterworth-Heinemann, Oxford

24. Dean A, Voss D (1999) Design and analysis of experiments. Springer, Berlin

25. NIST (2002) Inorganic crystal structure database, NIST Standard Reference Database Number 3, National Institute of Standards and Technology, Gaithersburg MD, https://doi.org/10.18434/M3214 7. Retrieved 082020

26. Giesting P, Porter N, Burns P (2006) Uranyl oxalate hydrates: structures and IR spectra. Z Krist Cryst Mater. https://doi. org/10.1524/zkri.2006.221.4.252

27. Rietveld H (1969) A profile refinement method for nuclear and magnetic structures. J Appl Crystallogr 2:65-71. https://doi. org/10.1107/S0021889869006558

28. Desgranges L, Baldinozzi G, Rousseau G, Niepce J, Calvarin G (2009) Neutron diffraction study of the in situ oxidation of $\mathrm{UO}_{2}$. ChemInform. https://doi.org/10.1021/ic9000889

29. Muhammed Shafi P, Chandra Bose A (2015) Impact of crystalline defects and size on X-ray line broadening: a phenomenological approach for tetragonal $\mathrm{SnO}_{2}$ nanocrystals. AIP Adv 5:057137. https://doi.org/10.1063/1.4921452

30. Ackermann R, Chang A, Sorrell C (1977) Thermal expansion and phase transformations of the $\mathrm{U}_{3} \mathrm{O}_{8}-\mathrm{z}$ phase in air. J Inorg Nucl Chem 39:75-85

31. Fillaux C, Berthet J, Conradson S, Guilbaud P, Guillaumont D, Hennig C, Moisy P, Roques J, Simoni E, Shuh D, Tyliszczak T, Castro-Rodriguez I, Den Auwer C (2007) Combining theoretical chemistry and XANES multi-edge experiments to probe actinide valence states. C.R. Chim. 10:859-871. https://doi.org/10.1016/j. crci.2006.12.012

32. Den Auwer C, Simoni E, Conradson S, Madic C (2004) Investigating actinyl oxo cations by X-ray absorption spectroscopy. Eur J Inorg Chem. https://doi.org/10.1002/ejic.200300093

33. Blake R, Hessevick R, Zoltai T, Finger L (1966) Refinement of the hematite structure. Am Mineral 51(1-2):123-129

34. Tamasi A, Cash L, Mullen W, Pugmire A, Ross A, Ruggiero C, Scott B, Wagner G, Walensky J, Wilkerson M (2016) Morphology of $\mathrm{U}_{3} \mathrm{O}_{8}$ materials following storage under controlled conditions of temperature and relative humidity. J Radioanal Nucl Chem 311:35-42. https://doi.org/10.1007/s10967-016-4923-1

35. Jayadevan N, Chackraburtty D (1972) The crystal and molecular structure of uranyl oxalate trihydrate. Acta Crystallogr B 28:3178-3182. https://doi.org/10.1107/S0567740872007691

36. Weck P, Kim E, Jové-Colón C, Sassani D (2012) Structures of uranyl peroxide hydrates: a first-principles study of studtite and metastudtite. Dalton Trans 41:9748. https://doi.org/10.1039/ C2DT31242E

37. Plášil J (2018) The crystal structure of uranyl-oxide mineral schoepite, $\left[\left(\mathrm{UO}_{2}\right)_{4} \mathrm{O}(\mathrm{OH})_{6}\right]\left(\mathrm{H}_{2} \mathrm{O}\right)_{6}$, revisited. J Geosci. https://doi. org/10.3190/jgeosci.252

38. Hawthorne F, Finch R, Ewing R (1995) Schoepite and dehydrated schoepite. MRS Proc. https://doi.org/10.1557/PROC-412-361

39. Morrell J, Jackson M (2013) Uranium Processing and Properties. Springer, Berlin

40. Idaho National Laboratory (2016) Comparison of nuclear fuels for TREAT: $\mathrm{UO}_{2}$ vs $\mathrm{U}_{3} \mathrm{O}_{8}$

41. Bès R, Rivenet M, Solari P, Kvashnina K, Scheinost A, Martin $P$ (2016) Use of HERFD-XANES at the U L3- and M4-Edges To determine the uranium valence state on $[\mathrm{Ni}(\mathrm{H} 2 \mathrm{O}) 4] 3[\mathrm{U}(\mathrm{OH}$, H2O)(UO2)8O12(OH)3]. Inorg Chem 55:4260-4270. https://doi. org/10.1021/acs.inorgchem.6b00014

42. Joseph K, Stennett M, Hyatt N, Asuvathraman R, Dube C, Gandy A, Govindan Kutty K, Jolley K, Vasudeva Rao P, Smith R (2017) Iron phosphate glasses: Bulk properties and atomic scale structure. J Nucl Mater 494:342-353. https://doi.org/10.1016/j.jnucm at.2017.07.015

43. Dehvari K, Lin K, Wang S (2016) Small angle x-ray scattering characterization of multifunctional iron oxide- pluronic nanocarriers: effect of temperature and drug encapsulation. Nanosci Nanotech Lett 8:667-670. https://doi.org/10.1166/nnl.2016.2210

44. Oakes M, Weber R, Lai B, Russell A, Ingall E (2012) Characterization of iron speciation in urban and rural single particles using XANES spectroscopy and micro X-ray fluorescence measurements: investigating the relationship between speciation and fractional iron solubility. Atmos Chem Phys 12:745-756. https:// doi.org/10.5194/acp-12-745-2012

45. Xiao J, He X, Hao J, Zhou Y, Zheng L, Ran W, Shen Q, Yu $G$ (2016) New strategies for submicron characterization the carbon binding of reactive minerals in long-term contrasting fertilized soils: implications for soil carbon storage. Biogeosciences 13:3607-3618. https://doi.org/10.5194/bg-13-3607-2016

46. Penn R (2004) Kinetics of oriented aggregation. J Phys Chem B 108:12707-12712. https://doi.org/10.1021/jp036490+

47. Jung Y, Son Y, Lee J (2012) 3-D self-assembly of flower-like particles via microwave irradiation for water treatment. RSC Adv 2:5877. https://doi.org/10.1039/c2ra20500a

48. Miyake K, Hirata Y, Shimonosono T, Sameshima S (2018) The effect of particle shape on sintering behavior and compressive strength of porous alumina. Materials 11:1137. https://doi. org/10.3390/ma11071137

49. Hyatt NC, Corkhill CL, Stennett MC, Hand RJ, Gardner LJ, Thorpe CL (2020) IOP Conf. Ser Mater Sci Eng 818:012022. https://doi.org/10.1088/1757-899X/818/1/012022

Publisher's Note Springer Nature remains neutral with regard to jurisdictional claims in published maps and institutional affiliations. 